BABELAO 5 (2016), p. 1-46

(C) ABELAO (Belgium)

\title{
Ci-gît Osiris.
}

\section{L'Abaton de Biggeh d'après les sources textuelles et iconogra- phiques}

Par

\section{Charly De Maré}

Université catholique de Louvain ${ }^{1}$

u $\mathrm{I}^{\mathrm{er}}$ millénaire avant notre ère, l'Abaton de Biggeh fut A un sanctuaire des plus importants, car il passait pour être le tombeau mythique d'Osiris. Située à la frontière méridionale de l'Égypte, dans le nome de Ta-Séty, l'île de Biggeh fait face à la rive occidentale de l'île de Philae, qui est consacrée à la déesse Isis. Si l'Abaton de Biggeh est le tombeau d'Osiris le mieux attesté dans les sources classiques, sa topographie est méconnue et n'a fait l'objet que de rares études ${ }^{2}$, à la différence des tombes d'Osiris à Busiris ${ }^{3}$, Abydos $^{4}$ et Oxyrhynchos 5 .

\footnotetext{
${ }^{1}$ Je remercie le Professeur Claude Obsomer (UCL) pour ses photographies et sa relecture, ainsi que Mme Marie-Cécile Bruwier (UCL - Musée royal de Mariemont) pour ses conseils avisés.

${ }^{2}$ H. JUNKER, Das Götterdekret über das Abaton (Denkschriften der Kaiserlichen Akademie der Wissenschaften 58.4), Vienne, 1913. Voir aussi P. Ковмотн, Osiris et les arbres : contribution à l'étude des arbres sacrés de l’Égypte ancienne (AegLeod 3), Liège, 1994.
} 
L'île est nommée

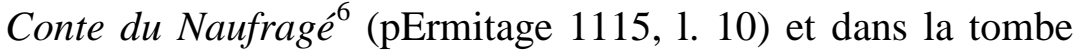
de Rekhmirê (TT100), où elle est présentée comme la véritable frontière de l'Égypte avec la Nubie ${ }^{7}$. L'espace sacré de la tombe d'Osiris est appelé 'A $\beta \alpha \tau o v$, l' " Inaccessible », dans la majeure partie des sources classiques, mais il est désigné comme $\checkmark$ I $I w w^{c} b$, «l'île pure $»^{8}$.

Si le toponyme Senmet s'applique bien à l'île de Biggeh ${ }^{9}$, il semble qu'il ait pu désigner un territoire cultivable du premier nome de Haute-Égypte bien plus étendu que la seule zone de l'Abaton $^{10}$. À l'époque ptolémaïque, Senmet englobait probablement tous les espaces cultivables, berges et îles en amont de la première cataracte, si bien que les textes égyptiens de l'époque insistent sur sa richesse agricole et prouvent son importance au sein du premier nome ${ }^{11}$. Dès l'époque ptolémaïque naît la confusion entre Senmet et l'Abaton, due au grand intérêt suscité par le tombeau d'Osiris. Progressivement, les textes vont néanmoins employer Snmt pour parler de l'île, mais 'I3t $w^{`} b t$ pour renvoyer précisément à l'Abaton ${ }^{12}$.

Au temple de Biggeh, le culte principal est celui d'OsirisOnnophris $^{13}$, mais Isis y est également vénérée. Un culte est

${ }^{3}$ S. Aufrere, J.-Cl. Goyon et J-Cl. Golvin, L’Égypte restituée : Sites et temples de Haute-Égypte, III, Paris, 1991, p. 184.

${ }^{4}$ É. AmÉlineAu, Mission Amélineau. Le Tombeau d'Osiris, monographie de la découverte faite en 1897-1898, Paris, 1899.

${ }^{5}$ H.I. AMER, «Les catacombes osiriennes d'Oxyrhynchos », dans L. Coulon (éd.), Le culte d'Osiris au I ${ }^{e r}$ millénaire av. J.-C. Découvertes et travaux récents, Paris, 2010, p. 269-282.

${ }^{6}$ Pour une édition de ce texte, voir A. M. BLACKMAN, Middle-Egyptian Stories (Bibliotheca Ægyptiaca II), Bruxelles, 1972, p. 42. Nous renvoyons à la traduction de G. LEFEBVRE, Romans et contes égyptiens de l'époque pharaonique, Paris, 1982, p. 32 sq.).

${ }^{7}$ A.H. GARDINER, Ancient Egyptian Onomasticon, II, Oxford, 1947, p. 2.

${ }^{8}$ K.H. BRUGSCH, Dictionnaire géographique de l'ancienne Égypte I, Leipzig, 1879, p. 464-466 et 1246 ; H. GAUTHIER, Dictionnaire des noms géographiques contenus dans les textes hiéroglyphiques II, Le Caire, 1925, p. 51 ; $W b$. I, p. 26 (14). Le terme $i 3 t$, « la butte », a été confondu tardivement avec iw, « l'île » : voir Wb. I, p. 26 (9).

${ }^{9}$ L'identification de Senmet avec l'île de Biggeh remonte à Champollion, pour qui le temple de Biggeh est « la deuxième édition d'un temple bien plus ancien et bien plus étendu, bâti sous le règne d'Aménophis III ». Voir J.-Fr. ChAmpollion, Lettres écrites d'Égypte et de Nubie en 1828-9, Paris, 1868, p. 166-167.

${ }^{10}$ Voir G. ZAKI, Le Premier Nome de Haute-Égypte du III ${ }^{e}$ siècle avant J.-C. au VII siècle après J.-C. d'après les sources hiéroglyphiques des temples ptolémaïques et romains (Monographies Reine Elisabeth, 13), Turnhout, 2009, p. 179.

${ }^{11}$ IDEM, p. 179-180.

12 IDEM, p. 227.

${ }^{13}$ IDEM, p. 267. 
également célébré en l'honneur de la triade d'Éléphantine : Khnoum-Rê $^{14}$, Satis, qui est assimilée à Sothis ${ }^{15}$, et Anoukis.

Il reste peu de choses du temple de Biggeh ${ }^{16}$. D'après Junker et Blackman ${ }^{17}$, l'île était sans doute à l'origine le sanctuaire principal de la zone, avant d'être supplantée par Philae en raison de la taille réduite de son temple. Selon Blackman, les fondations du temple seraient antérieures à la période ptolémaïque, mais il est impossible d'explorer les strates inférieures, les fondations ayant été cimentées en vue de stabiliser l'édifice ${ }^{18}$. Construit sous Ptolémée XIII et agrandi sous Auguste ${ }^{19}$, le temple de Biggeh, tel qu'il est conservé, date donc de l'époque gréco-romaine. Le sanctuaire est dominé par une grande arche d'époque romaine. Une église fut installée au VII ${ }^{\mathrm{e}}$ siècle dans son naos ${ }^{20}$. On observe encore les vestiges d'un quai face au pylône, les restes d'un propylône avec deux môles garnis de corniches à gorge et suivis de deux colonnes composites. Mais « il ne reste plus rien de la partie proprement osirienne, le lieu où devait se trouver la crypte mystérieuse où se régénérait le corps d'Osiris $»^{21}$.

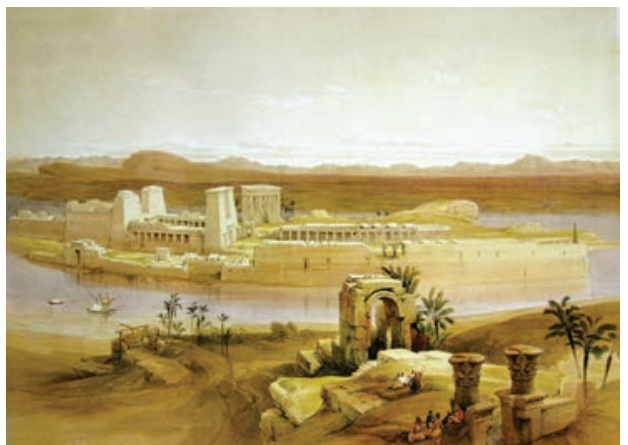

Fig. 1. David Roberts, General View of the Island of Philae $(1838)^{22}$

\footnotetext{
${ }^{14}$ Alors que son culte est attesté dès le Moyen Empire à Biggeh dans des inscriptions, Khnoum aurait subi le succès de Philae et l'installation à Biggeh des divinités liées au mythe osirien. Voir E. WINTER, «Bigga ", dans LÄ I, Wiesbaden, 1975, col. 792-793 ; É. DRIOTON, « Philae, île sacrée ", dans Courrier de l'UNESCO, Paris, février 1960, p. 36.

${ }^{15}$ Selon P. MonTET, Géographie de l'Égypte ancienne, Paris, 1957, p. 23-24, l'introduction de Sothis en Ta-séty est récente, et l'on ne s'explique pas très bien comment elle s'est assimilée à Satis d'Éléphantine (cf. ciaprès, note 77).

${ }^{16}$ G. ZAKI, Le Premier Nome de Haute-Égypte, Turnhout, 2009, p. 267.

17 H. Junker, op. cit., p. 45 ; A.M. BlaCKMAN, The temple of Bîgeh (Les Temples immergés de la Nubie), Le Caire, 1915, p. 1-2.

${ }^{18}$ L. MANNICHE, "Osiris’ grav og tempel på Biga », dans Papyrus: Egyptologisk tidsskrift 32.2 (2012), p 4-15 ; A.M. BLACKMAN, op. cit., p. 2.

${ }^{19}$ A.M. BLACKMAN, op. cit., p. 2 ; É. DRIOTON, loc. cit., p. 36.

${ }^{20}$ P. GROSSMANN, "Überlegungen zur Gestalt der Kirche im Tempel von Biga ", dans T.A. BACZ, A Tribute to Excellence. Studies offered in Honor of Erno Gaal, Ulrich Luft, Laszlo Torok (Studia Aegyptiaca, 17), Budapest, 2002, p. 279-287.

${ }^{21}$ G. ZAKI, op. cit., p. 379.

${ }^{22}$ Issu de Egypt and Nubia, s. 1., 1846-1849; image tirée de https://commons.wikimedia.org/wiki/File:David_Roberts_Temple_Island_P hilae.jpg. (consulté le 08/03/2016).
} 
En 1838, le peintre anglais David Roberts peint une vue de Philae montrant à l'avant-plan les vestiges du temple de Biggeh (fig. 1). Des séismes et la stabilisation des murs au moyen de ciment sont responsables de la détérioration du site. De surcroît, les vestiges avaient été en partie engloutis par le lac de retenue formé à la suite de la construction du premier barrage d'Assouan en 1902 (fig. 2) ${ }^{23}$.

Quoi qu'il en soit, les vestiges du temple sont encore debout, à moitié cachés dans les arbres et arbustes de la crique orientale de Biggeh $^{24}$. L'aspect actuel des paysages du territoire cultivable de Senmet ne ressemble plus à la végétation verdoyante qui était présente à l'époque ptolémaïque, lorsque les débordements annuels du fleuve fertilisaient la région ${ }^{25}$. Mais il reste possible d'imaginer la «Butte pure» de l'époque antique comme un vaste bosquet à la végétation luxuriante.

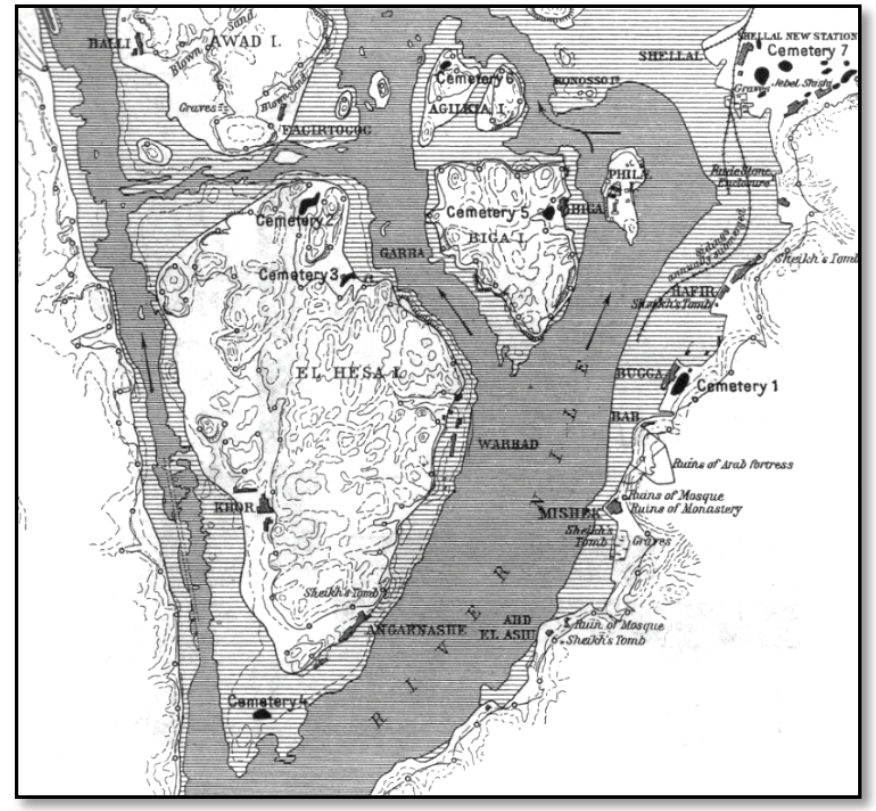

Fig. 2. Carte de H. JUNKER, Das Götterdekret über das Abaton, Vienne, 1913, p. $48^{26}$

De nos jours, l'île de Biggeh est entourée d'autres îles qui parsèment la zone méridionale de la première cataracte : Agilkiya (où fut reconstruit le temple de Philae), El-Heseh, Konosso. Parsemée de rochers de granit érodés, elle est de forme allongée et orientée selon un axe nord-sud. Ses berges abruptes offrent des falaises et une crique sur la côte orientale qui fait

\footnotetext{
${ }^{23}$ S. CAUVILle et M. IBrahim Ali, Phile : Itinéraire du visiteur, Louvain, 2013, p. 257.

${ }^{24}$ L. MANNICHE, loc. cit., p 4-15.

${ }^{25}$ Voir G. ZAKI, op. cit., p. 178.

26 Je remercie la maison d'édition de l'Österreichische Akademie der Wissenschatften (http://verlag.oeaw.ac.at/) de m'avoir autorisé à reproduire certaines illustrations de cet ouvrage.
} 
face à l'ancienne île de Philae, aujourd'hui sous les eaux. Biggeh et Philae sont séparées par un étroit chenal d'environ $80 \mathrm{~m}$ de large $\mathrm{e}^{27}$. L'accès à Biggeh n'est pas autorisé, car il est dangereux de s'en approcher en bateau motorisé en raison des écueils. Dès lors, très peu de gens s'y aventurent. Les ruines sont connues sous le nom de al Ma'abad al-Qadîma, "le temple antique ${ }^{28}$.

Compte tenu des lacunes archéologiques, nous avons souhaité étudier l'ensemble des textes consacrés à l'Abaton de Biggeh, afin de permettre une meilleure connaissance de l'île sacrée et une meilleure compréhension de son organisation spatiale. L’intérêt se centrera sur la topographie locale, qu'elle soit réelle ou mythique, et les rituels qui y sont célébrés. Quelle vision de l'Abaton nous offrent les sources textuelles? Dans quelle mesure les sources classiques et les sources égyptiennes sont-elles convergentes ? À quel point leurs descriptions sontelles vraisemblables? Telles sont les questions auxquelles nous tenterons de répondre.

Nous présenterons d'abord les sources égyptiennes dans l'ordre chronologique, en proposant notamment une traduction personnelle du Décret divin concernant l'Abaton de Biggeh, et nous détaillerons les reliefs de la Porte d'Hadrien liés à ce Décret. Nous étudierons ensuite les sources classiques en les traduisant et en les commentant, également dans leur ordre chronologique. Le corpus établi par Junker en $1913^{29}$, qui incluait Diodore de Sicile, Sénèque, Plutarque et Servius, sera complété avec le passage de Strabon qui traite de l'interdiction de la musique, un extrait de Lucain et un autre de Claudien.

Les sources textuelles vont du $\mathrm{I}^{\mathrm{er}}$ siècle avant notre ère au $\mathrm{V}^{\mathrm{e}}$ siècle de notre ère : elles sont donc assez tardives en regard de la réalité du culte local qui dut connaître son apogée à la Basse Époque (712-333) et à l'époque ptolémaïque (332-31). Notre objectif est de récolter les informations pertinentes en vue d'une confrontation avec les sources égyptiennes.

\section{Les sources égyptiennes}

\section{A. La liste géographique d'Edfou}

La liste géographique d'Edfou, qui date de Ptolémée IV Philopator (222-205), est gravée dans le couloir mystérieux sur le pourtour du sanctuaire (paroi nord, série gauche) : elle figure au registre inférieur, au sein du défilé des nomes de Haute-Égypte. La légende qui accompagne la figuration du nome de Ta-séty,

\footnotetext{
${ }^{27}$ Voir Ch. LEITZ, Quellentexte zur ägyptischen Religion I : Die Tempelinschriften der griechisch-römischen Zeit, Berlin, 2009, p. 44.

${ }^{28}$ L. MANNICHE, loc. cit., p 4 et p. 14, note 1.

${ }^{29}$ H. JUNKER, Das Götterdekret über das Abaton, Vienne, 1913.
} 
sous la forme d'un génie Hâpy tenant un plateau d'offrandes, donne des indications sur le nome dans son ensemble.

La mention que l'on y trouve de l'Abaton est la suivante ${ }^{30}$ :

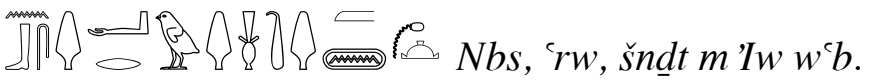
Le jujubier, l'arbre- \&w (et) l'acacia sont dans l'Île pure.

Le bosquet sacré tombe d'Osiris de l'Abaton ${ }^{32}$, comportait différentes espèces d'arbres : des palmiers-dattiers (phoenix dactylifera, ég. bnrt) évoqués par les offrandes de palmes dans le Décret I ( $c f$. infra) et liés à l'utilisation rituelle des dattes ${ }^{33}$, ainsi qu'un jujubier (ziziphus spina Christi, ég. $n b s)^{34}$, un arbre- $r w$ non identifié ${ }^{35}$, et un acacia (acacia nilotica, ég. $\check{s} n \underline{d} t$ ). Notons que le jujubier et l'acacia sont des arbres épineux et fruitiers : le premier donne des fruits comestibles nommés «jujubes" et le second des fruits sous forme de gousses contenant des graines. Selon nous, les arbres à épines avaient pour fonction de protéger la tombe du dieu.
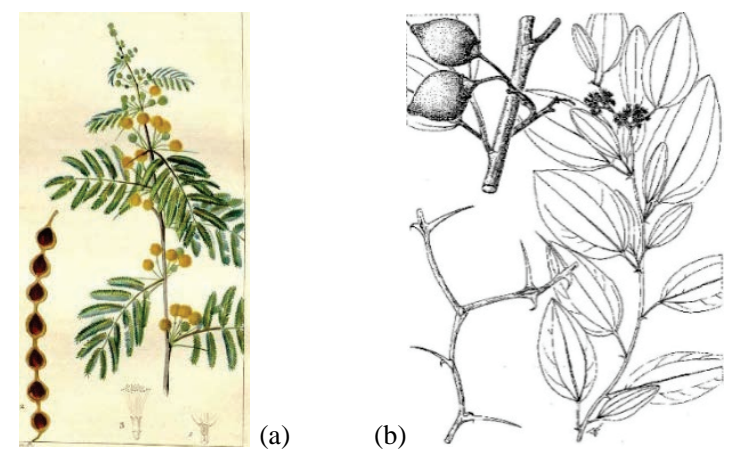

Fig. 3. (a) Branche et gousse d'Acacia nilotica

(F. P. CHAUMETON et alii, Flore médicale, I.1, 1833, pl. II)

(b) Branche et fruits du Ziziphus spina Christi ${ }^{36}$

Par ailleurs, les arbres fruitiers symbolisent pleinement le caractère nourricier d'Osiris. Le pJumilhac X, 13-15, rapporte que la même association d'arbres ( $n b s$, ' $r w$ et $\check{s} n \underline{d} t)$ se trouvait dans le $18^{\mathrm{e}}$ nome de Haute-Égypte, sur les $i 3 t$ de Dounanouy, consacrées aux acteurs du mythe osirien ${ }^{37}$. Les arbres du bosquet $m n t$ ’ bordaient un canal entourant le tombeau d'Osiris ( $c f$.

${ }^{30}$ Édition : É. CHASsinAt, Le temple d'Edfou I, Le Caire, 1897, p. 337 (3-8) et pl. XV. Traduction complète de la légende : G. ZAKI, op. cit., p. 6-7.

${ }^{31}$ Voir Wb. II, p. 91 (13-14).

${ }^{32}$ H. JUNKER, op. cit., p. 50-51 et 58.

33 Dans le cadre des Mystères osiriens, la pulpe de dattes est un des ingrédients nécessaires à la confection de la figurine du Sokar.

${ }^{34}$ Voir R. GERMER, Flora des pharaonischen Ägypten (SDAIK 14), Mayence, 1985, p. 114 ; N. BAUM, Arbres et arbustes de l'Égypte ancienne. La liste de la tombe thébaine d'Inéni (OLA 31), Louvain, 1988, p. 169.

${ }^{35}$ Voir N. BAUM, op. cit., p. 326.

36 Illustration tirée de http://www.ethnopharmacologia.org/recherchedans-prelude/?plant_id=13310\#lightbox[13310]/5/ (consulté le 08/03/2016).

${ }^{37}$ Voir N. BAUM, op. cit., p. 326. 
infra). Le reverdissement des arbres du bosquet prenait une signification osirienne ${ }^{38}$.

Le jujubier est lié à Thot de $\operatorname{Pr} n b s$ (Pnoubs) ${ }^{39}$, lui-même associé au mythe de la déesse lointaine et à l'anéantissement des ennemis d'Osiris ${ }^{40}$. La « fine stature légèrement penchée ${ }^{41} \mathrm{du}$ palmier-dattier rappelle Isis implorante, et ses fruits sont doux comme les paroles de la déesse. Dans le pJumilhac XIV, 11-12, le palmier-dattier est décrit comme une hypostase d'Isis, sur base d'un calembour entre les termes bnrt, "palmier-dattier » et $b n r$, "doux ». La fonction maternelle attribuée au palmierdattier est significative, puisqu'il est habité par des divinités célestes et nourricières, de même que le sycomore ${ }^{42}$. Néanmoins, une autre interprétation est possible. En effet, dans le pJumilhac VIII, 20-23, les palmiers-dattiers sont la manifestation végétale des lymphes d'Osiris ${ }^{43}$. Quant à l'arbre- $r w$, dont l'espèce n'est pas encore identifiée, Osiris s'assimile à lui dans le Rituel de l'Embaumement, au chapitre 9, qui mentionne les deux cuisses d'Osiris, la relique de Biggeh, d'où le Noun fait jaillir l'inondation ${ }^{44}$. Le pSalt 825 mentionne aussi l'arbre- $r w$ : "Quant à l'arbre-' $r w$ de l'Occident, il se dresse pour Osiris pour l'affaire qui est arrivée sous lui », c'est-à-dire son inhumation $^{45}$. En effet, l'arbre- $r w$ était planté à l'emplacement des tombes osiriennes. L'acacia symbolise aussi Osiris, «Celui qui est dans l'acacia " ${ }^{46}$, si bien que le lieu de la tombe d'Osiris dans le $21^{\mathrm{e}}$ nome de Haute-Égypte était nommé en grec

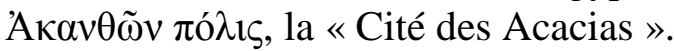

${ }^{38} \mathrm{P}$. KоEмоTH, Osiris et les arbres : contribution à l'étude des arbres sacrés de l'Égypte ancienne (AegLeod 3), Liège, 1994, p. 119.

${ }^{39}$ Pnoubs est une ville de Nubie, éponyme du jujubier. Thot de Pnoubs serait d'abord Thot de l'arbre- $n b s$ ( $p$ ’ $n b s$ ), puis éventuellement Thot de la localité ( $\operatorname{Pr} n b s$ ), selon D. InCONNU-BOCQUILlON, « Thot de Pnoubs (la ville) ou du nebes (l'arbre) », dans Revue d'Égyptologie 39 (1988), p. 47-62.

40 Voir N. BAUM, Arbres et arbustes de l'Égypte ancienne, Louvain, 1988, p. 173-174. Cet arbre est lié aux deux mythes importants de Biggeh, celui d'Osiris et celui de la déesse lointaine. Il a donc un symbolisme particulièrement fort sur l'île sacrée.

${ }^{41}$ N. Gullhou, La mythologie égyptienne, Paris, 2005, p. 290.

${ }^{42}$ N. BAUM, op. cit., p. 261.

${ }^{43}$ S. AUfRÈRE, Encyclopédie religieuse de l'univers végétal : Croyances phytoreligieuses de l'Égypte ancienne I, Montpellier, 1999, p. 239.

${ }^{44}$ Voir J.-Cl. Goyon, Rituels funéraires de l'Ancienne Égypte, Paris, 1972, p. 68 et 70. L'Inondation personnifiée (Hâpy) a été étroitement identifiée à Osiris par les hiérogrammates de Basse Époque : voir J. YOYOTTE, "Études géographiques I. La “Cité des Acacias” (Kafr Ammar) », dans RdÉ 13 (1961), p. 104.

${ }^{45}$ Voir Fr.-R. HERBIN, Le livre de parcourir l'éternité (OLA 58), Leuven, 1994, p. 211 ; Ph. DERCHAIN, Le Papyrus Salt 825 (B. M. 10051), rituel pour la conservation de la vie en Égypte, Bruxelles, 1965, p. 159-160, note 45.

${ }^{46}$ J. YoyotTe, loc. cit., p. 100 ; J.-P. CORTEGGIANI, L’Égypte ancienne et ses dieux : dictionnaire illustré, Paris, 2007, p. 9. 


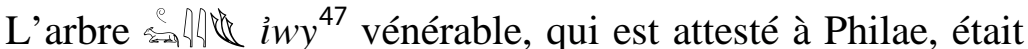
distinct du bosquet $m n t^{3}$ et s'élevait sur la tombe d'Osiris ${ }^{48}$. Le déterminatif de la plante (et non de l'arbre comme dans l'extrait présenté) évoque le caractère nourricier et verdoyant de ce $i w y$ vénérable ${ }^{49}$. Il n'indique pas qu'il s’agit nécessairement d'une plante basse, comme le montre la représentation de l'arbre à Philae (voir fig. 4). De surcroît, le bosquet, composé d'arbres à silhouette haute, est lui aussi déterminé par le signe de la plante dans le Décret I (1. 5, cf. infra). Junker n'identifie pas cet arbre à une espèce particulière et ne résout pas les divergences présentes entre les sources égyptiennes. En se fondant sur les sources textuelles et iconographiques, nous pouvons affirmer qu'il est question d'un arbre imposant, qui serait un grand sycomore (ficus sycomorus), appelé nht wrt dans les sources égyptiennes ${ }^{50}$, et surnommé, selon nous, le « iwy vénérable ».

Les arguments en faveur d'une identification de cet arbre avec le sycomore sont nombreux. D'abord, la forme de l'arbre sur la représentation de Philae correspond bien à l'iconographie du sycomore ${ }^{51}$. En revanche, l'arbre išd a une forme moins compacte. De plus, le sycomore est lié à Nout-Hathor, nourricière des défunts ${ }^{52}$, présente dans le relief de Philae (fig. 4) et au fond des sarcophages en bois de sycomore. Ensuite, une stèle de Psammétique II et un texte du temple de Dakka attestent la présence d'un sycomore à Biggeh ${ }^{53}$. Le sycomore et le palmier-dattier sont souvent associés dans les nécropoles ou les jardins funéraires ${ }^{54}$. Enfin, les branches de sycomore sont utilisées dans les Mystères d'Osiris pour fabriquer la figurine du Sokar figurant Osiris roi des défunts ${ }^{55}$. La formule 574 des

${ }^{47}$ Wb. I, p. 49 (20) : il s'agit d'un arbre ou d'un arbuste.

${ }^{48}$ D'après les inscriptions de Philae, « le sarcophage reverdit, l'arbre íwy vénérable de Biggeh », ou encore "l'arbre i $i w y$ vénérable reverdit en vie »: voir H. JUNKER, op. cit., p. 52-53.

${ }^{49}$ Sur ce point, nous suivons P. Kовмотн, op. cit., p. 116 et 119. En faveur de l'arbrisseau ou plante iwy : N. BAUM, op. cit., p. 309.

${ }^{50}$ Voir H. JUNKER, op. cit., p. 14 ; P. КоEMOTH, op. cit., p. 31 ; p. 71.

${ }^{51}$ Voir N. BAUM, op. cit., p. 27 ; forme très proche des sycomores de la tombe de Rekhmirê : voir N. DAVIES, The Tomb of Rekh-mi-Rê at Thebes, New York, 1943, planche 110.

${ }^{52}$ Voir H. JUNKER, op. cit., p. 14 ; J.-P. CORTEGGIANI, op. cit., p. 525527. Il est question dans une inscription de Philae de «faire vivre le grand sycomore avec le lait de la vache noire ».

${ }^{53}$ H. GOEDICKE, «The campaign of Psammetik II against Nubia », dans MDAIK 37 (1981), p. 187-198; G. RoEDER, Der Tempel von Dakke I, Le Caire, 1930, p. 147-148.

${ }^{54}$ Voir N. BAUM, op. cit., p. 275-276.

${ }^{55}$ É. ChASsinAt, Le mystère d'Osiris au mois de Khoïak, Le Caire, 1966. Les Mystères d’Osiris sont des célébrations réservées aux prêtres commémorant le meurtre et la régénération d’Osiris, en lien avec la montée concomitante de l'inondation. D'origine abydénienne, les Mystères se répandent dans les grandes villes durant le $\mathrm{I}^{\mathrm{er}}$ millénaire avant notre ère, si 
Textes des Pyramides fait référence à sa fonction protectrice du tertre de la tombe d'Osiris ${ }^{56}$.

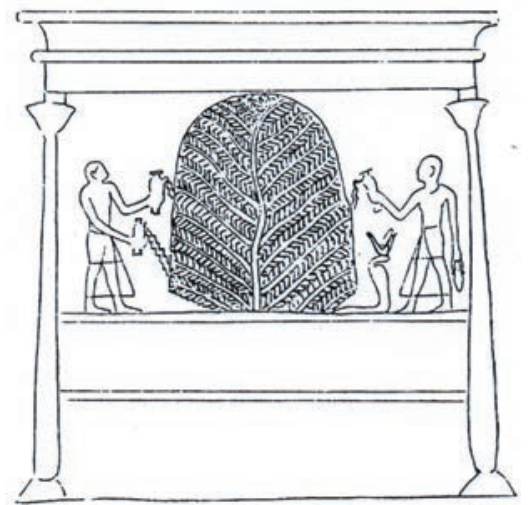

Fig. 4. Porte d'Hadrien : l'arbre iwy vénérable de Biggeh

(H. JunKER, Das Götterdekret über das Abaton, Vienne, 1913, p. 52, fig. 17).

Selon Koemoth, «l'arbre pousserait en fait sur la tombe installée entre quatre colonnes reliées deux à deux par une corniche, l'ensemble étant à ciel ouvert ${ }^{57}$ et formant une espèce de baldaquin funéraire ${ }^{58}$ qui représentait sans doute la Douat supérieure $^{59}$. L'uraeus coiffé de la couronne hathorique qui sort des rameaux de l'arbre n'est autre qu'Hathor-Tefnout protégeant la sépulture ${ }^{60}$. Le tertre sur lequel l'arbre s'épanouit, logiquement situé en-dessous, n'est pas visible. Au niveau symbolique, l'arbre iłwy vénérable était une hypostase d'Osiris reverdissant ; il matérialisait la présence et l'énergie d'Osiris ressuscité à Biggeh ${ }^{61}$. C’est pourquoi des libations étaient versées au pied de l'arbre afin de garantir la régénération du dieu.

Ainsi, les diverses espèces d'arbres évoquent soit Osiris luimême soit les protagonistes du mythe d'Osiris (Isis, Thot) qui manifestent leur présence et témoignent de leur attention à l'égard du dieu défunt.

\section{B. Les inscriptions du temple de Biggeh}

Les inscriptions du temple de Biggeh montrent que les acteurs principaux du mythe de la Lointaine, la déesse Hathor-

bien qu’à l'époque ptolémaïque chaque ville prétend posséder une partie de la dépouille d'Osiris. En réalité, les reliques sont des simulacres de parties du corps osirien (le Lambeau divin), fabriquées chaque année puis enterrées, en même temps que des figurines de la momie entière (le Khenty Imentiou et le Sokar).

${ }^{56}$ N. GuILHOU, La mythologie égyptienne, Paris, 2005, p. 295.

${ }^{57} \mathrm{P}$. KоемотH, Osiris et les arbres : contribution à l'étude des arbres sacrés de l'Égypte ancienne (AegLeod 3), Liège, 1994, p. 82.

${ }^{58}$ Voir JUNKER, op. cit., p. 52 ; P. KOEMOTH, op. cit., p. 82.

${ }^{59}$ La Douat supérieure désigne généralement une chapelle établie sous un arbre sacré et constitue le lieu d'inhumation temporaire des simulacres osiriens. La Douat inférieure désigne la crypte située sous le tertre et faisant office de lieu d'inhumation définitif.

${ }^{60}$ P. КOEMOTH, op. cit., p. 83.

${ }^{61}$ Ibidem. 
Tefnout et le dieu Thot, bénéficiaient d'un culte dans ce sanctuaire $^{62}$. Mais il semble clair que l'Abaton était consacré principalement à Osiris et Isis ${ }^{63}$. Nombreuses sont, en effet, les inscriptions de ce temple qui concernent la triade de Philae (Isis, Osiris et Harpocrate) de même que la théologie osirienne $^{64}$, utilisant parfois une phraséologie assez emphatique ${ }^{65}$. De plus, les sources classiques corroborent cette affirmation.

\section{La Porte d'Hadrien à Philae}

La principale source égyptienne qui décrit l'Abaton de Biggeh se trouve à Philae, dans le couloir de l'embarcadère menant à l'île de Biggeh, une structure appelée «Porte d'Hadrien » ou "Portique d'Osiris ». L'on y voit deux exemplaires d'un décret concernant l'Abaton de Biggeh datant du règne de l'empereur Hadrien (117-138), associés à une série de reliefs figurés.

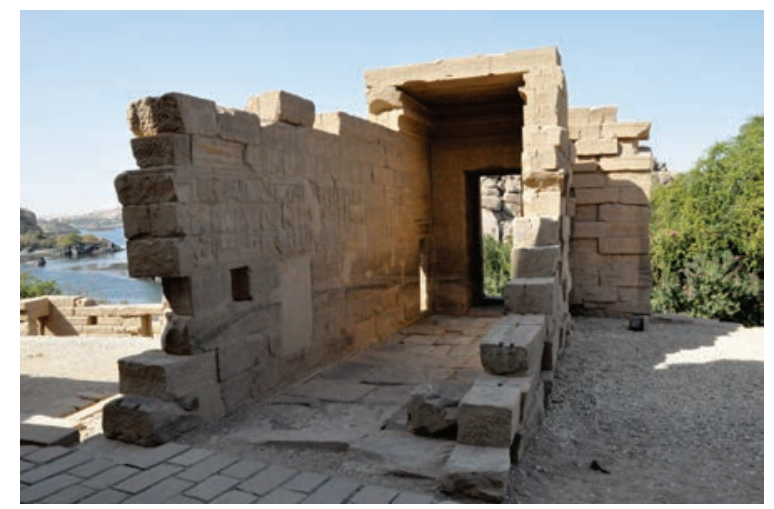

Fig. 5. La Porte d'Hadrien à Philae

\section{Le décret divin sur l'Abaton de Biggeh}

Des deux exemplaires du décret sur la Porte d'Hadrien, c'est le « Décret I » qui est le plus complet : il comporte une dizaine de colonnes. L'étude philologique la plus complète à ce jour date de 1913 et est l'œuvre de Junker ${ }^{66}$. Il est donc opportun de réexaminer le texte en utilisant les ouvrages de référence plus

\footnotetext{
${ }^{62}$ H. JUNKER, op. cit., p. 45 ; A. ERMAN, La Religion des Égyptiens, Paris, 1952, p. 431-434 ; P. КОЕмОTH, op. cit., p. 82.

${ }^{63}$ E. WINTER, « Wem war der Tempel von Bigge geweiht? », dans Studia Aegyptiaca I, Budapest, 1974, p. 399-406 ; «Bigga », dans LÄ I, Wiesbaden, 1975, col. 792-793.

${ }^{64}$ A.M. BLACKMAN, The temple of Bîgeh (Les Temples immergés de la Nubie), Le Caire, 1915, passim.

65 IDEM, p. 22 : «Osiris maître du monde » (Wsir $n b t$ ), «prince des dieux » (hry ntrw).

${ }^{66}$ H. JUNKER, Das Götterdekret über das Abaton (DAWW 58), Vienne, 1913 (ci-après JUNKER). Voir aussi Ch. LEITZ, Quellentexte zur ägyptischen Religion I: Die Tempelinschriften der griechisch-römischen Zeit, Berlin, 2009, p. 44-48.
} 
récents de Daumas et de Wilson ${ }^{67}$. Le texte hiéroglyphique est celui établi par Junker, auquel s'ajoutent quelques considérations sur des questions de lecture de signes notamment. La traduction proposée a bénéficié de la consultation de celles de Roeder et de Yoyotte (partielle) ${ }^{68}$.

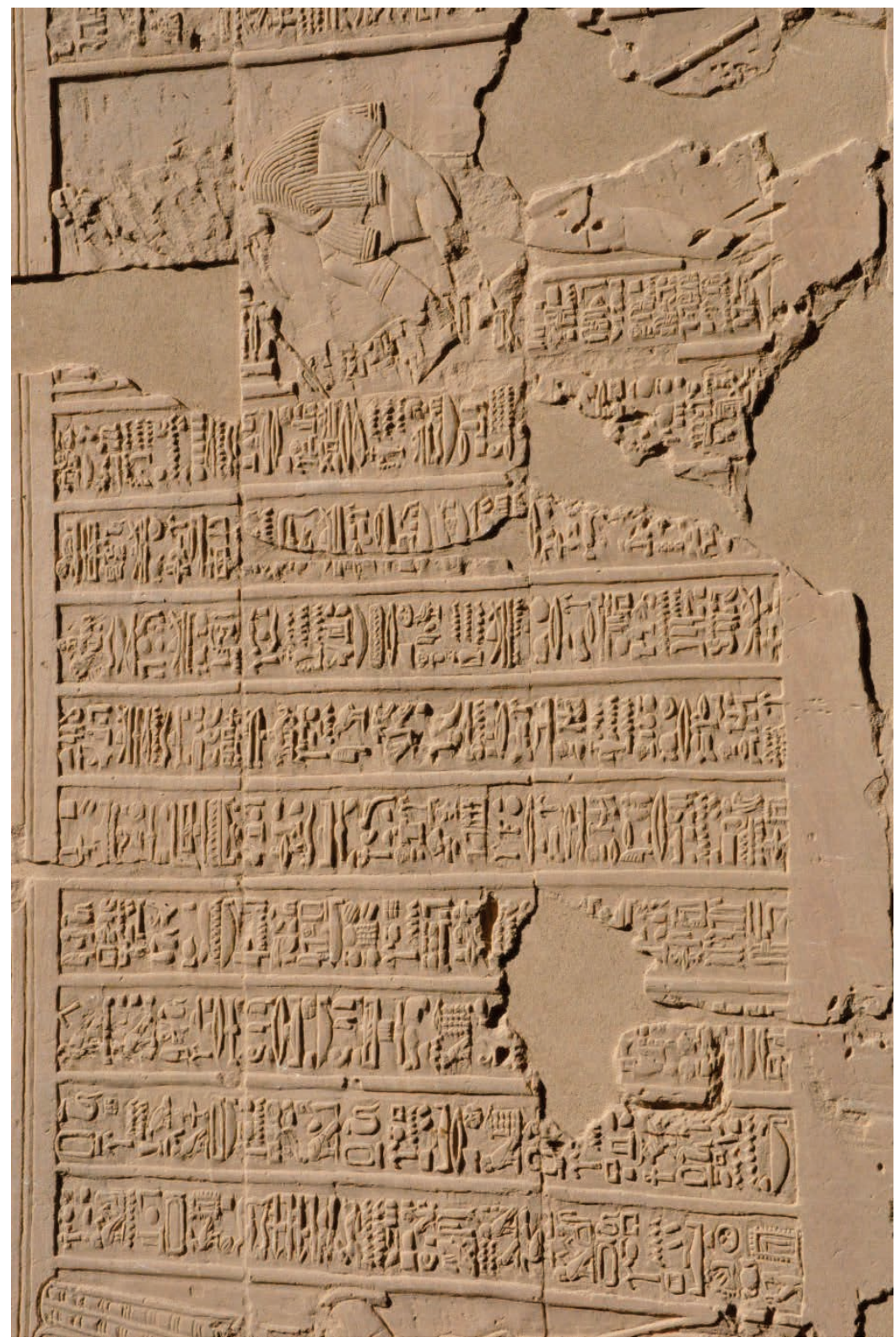

Fig. 6. Le Décret I de la Porte d’Hadrien

${ }^{67}$ Fr. DAUMAs et alii, Valeurs phonétiques des signes hiéroglyphiques d'époque gréco-romaine, Montpellier, 1988-1995 (ci-après DAUMAS); P. WILson, Ptolemaic Lexikon: a Lexicographical Study of the Texts in the Temple of Edfu, Louvain, 2000 (ci-après WILSON).

${ }^{68}$ G. RoEDER, Urkunden zur Religion des alten Ägypten, Iena, 1915, p. 31-33 (ci-après RoEder) ; J. YoyotTE, P. CHARVET et S. GOMPERTZ, Strabon. Le voyage en Égypte, Paris, 1997, p. 260-261 (ci-après YOYOTTE). Autres traductions : É. DRIOTON, "Philae, île sacrée ", dans Courrier de l'UNESCO, Paris, février 1960, p. 36 ; S. CAUVILle, M. IBRAHIM Ali, Philæe : Itinéraire du visiteur, Louvain, 2013, p. 268-269. 
À destination des lecteurs qui ne pratiquent pas le ptolémaïque, voici une liste de valeurs phonétiques notables de signes récurrents (dans leur ordre d'apparition) :

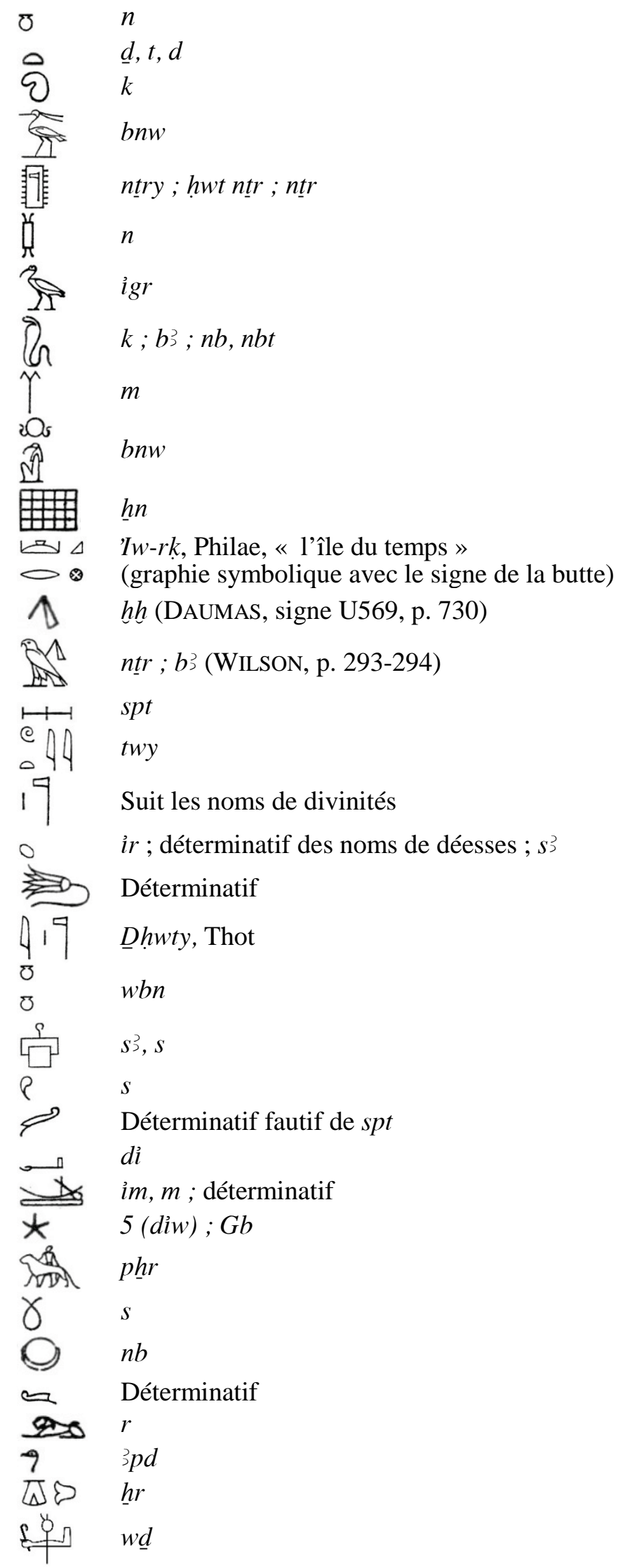




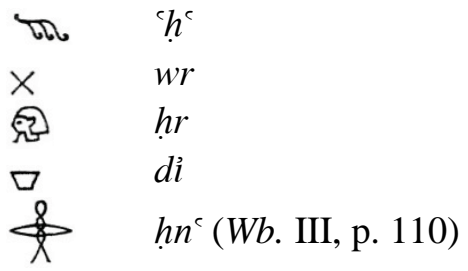

\section{1a. L'hymne adressé au Ba d'Osiris}

Formule d'invocation

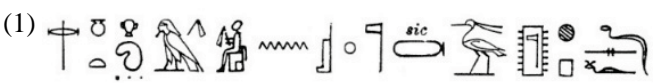

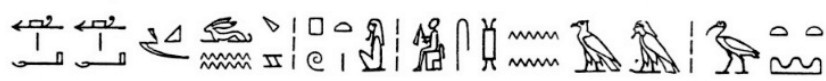

(1) 'Ind hr.k, $b$ ว šps $n(y) W \operatorname{sir}(W n n-n f r) \mid$ ! Bnw ${ }^{69} n t r y^{70} h p(r w)$ $\underline{d} s . f, w^{c} w^{c}, k m \jmath(w) w n n w, p(3) w t(y)$ šps $n(y) n \supset b^{\jmath} w^{\prime} \operatorname{Igrt}^{71}$.

(1) Salut à toi, $B a^{72}$ vénérable d'Osiris Ounen-néfer! Phénix divin $^{73}$ qui s'est engendré lui-même, l'Unique à être unique ${ }^{74}$, qui a créé ce qui est, dieu primordial vénérable des Baou de l'Au-delà.

\section{Litanie sur les noms du Ba d'Osiris}

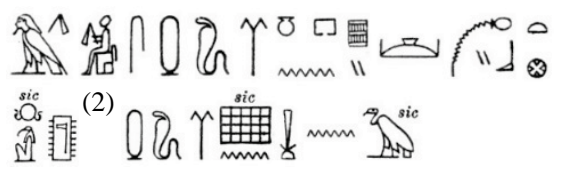

${ }^{69}$ Valeur bnw du signe G603 dans DAUMAS, p. 322. La lecture bnw est également proposée par H. W. FAIRMAN, dans ASAÉ 43 (1943), p. 269.

${ }^{70}$ Valeur ntry du signe 0675 dans DAUMAS, p. 501. La lecture ntry est due à JUNKER, p. 8, n. 26, sur base d'une comparaison avec des signes de forme semblable (O679 entre autres).

${ }^{71}$ Valeur igr du signe 513 dans Daumas, p. 317. Voir WILSON, p. 118 ; Wb. I, p. 141 (4).

${ }^{72}$ Le Ba d'un dieu est la manifestation de son pouvoir dans le monde sensible, rendue visible pour les hommes (phénomènes naturels, étoiles, etc.). Il descend dans la statue divine chaque jour dans le temple afin de perpétuer sa puissance en se nourrissant des offrandes des hommes. Le Ba d'Osiris faisait l'objet d'un culte propre sous la forme d'oiseau à tête humaine sur l'Abaton.

${ }^{73}$ Osiris est invoqué à la fois en tant que démiurge à travers son assimilation à Rê-Atoum (il est celui « qui s'est engendré lui-même » et fait figure de "dieu primordial " dans notre texte) et en tant que dieu lié à la renaissance cyclique des forces naturelles, notamment à travers l'inondation et la Lune ( "Phénix/héron- $b n w$ divin »). En effet, selon Guilhou, le héron- $b n w$, forme du démiurge Rê-Atoum à Héliopolis représentant généralement la renaissance solaire, peut être une manifestation lunaire d'Osiris ; il est alors associé au héron- $b^{\complement} h$, symbolisant la profusion de la crue annuelle. Ainsi, les deux formes de « phénix » en Égypte reflètent le cycle de la création et de la (re)naissance. Voir N. GuILhou, La mythologie égyptienne, Paris, 2005, p. 342-343. De surcroît, Osiris-Lune faisait l'objet d'un culte à Biggeh.

$74 \mathrm{Au}$ commencement du monde, le démiurge, Osiris-Atoum, fut « l'Unique à être unique », puis il «se transforma en millions » par son œuvre de création. Voir E. HoRnUNG, Les dieux de l'Égypte : le Un et le Multiple, Paris, 1986, p. 169. 


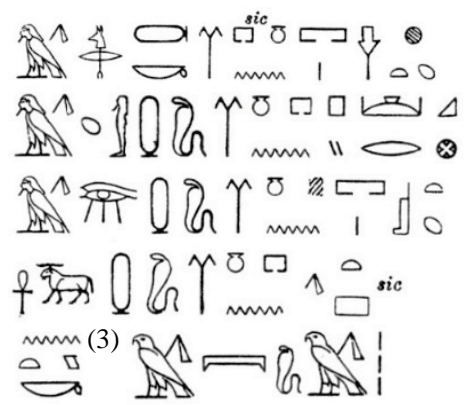

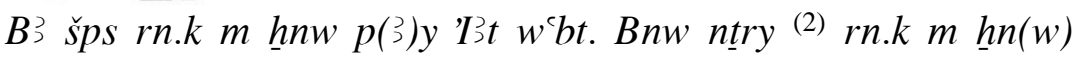
Snmwt. Bз wsr ${ }^{75}$ rn.k $m$ hnw Pr-Shmt. B $3<s p d>^{76}$ irw rn.k $m$ hnww p(ว)y 'Iw-rk. B’ rmy rn.k $m$ hnww Pr-зst. B’ 'nh rn.k $m$ hnww $H h t^{77} . N t k^{(3)} b$ ว $h r(y) b^{378} n t r w$.

${ }^{75}$ Comme l'indique Junker, p. 4, il y sans doute un lien entre le nom de $b$ ว wsr d'Osiris et Sekhmet (wsrt, la « Puissante »). De surcroît, un hymne à Isis-Ouseret-Sekhmet est conservé à Edfou (É. CHASSINAT, Le temple d'Edfou III, Le Caire, 1897, p. 316, 13-14). D’après G. Zaki, op.cit., p. 197, Isis est nommée «la Puissante » dans son rôle de "gardienne tutélaire du Sud et de sa position stratégique ».

${ }^{76}$ Restitution de JunKER, p. 4, sur base de l'incohérence fondamentale de $b$ ว irw et de parallèles. Le signe omis pour spd correspond au Z59 dans DAUMAS, p. 830 ; par ailleurs, la ressemblance entre les signes spd et ir suffit pour expliquer l'oubli du premier.

77 Comme RoEDER semble l'avoir compris d'après sa traduction, le toponyme n'est pas Hépet, qui serait selon JUNKER, p. 5, un lieu de culte non identifié probablement dédié à Khnoum et Satet, mais Éléphantine. En effet,

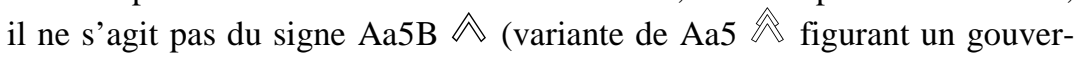
nail, translittéré $h p, h p t$ ), mais du signe U97A $\mathbb{A}$ (variante de U97 représentant un instrument d'arpentage, translittéré $h$ h ) dont une variante $\widehat{\uparrow}$, qui omet le fil à plomb et le cœur, est attestée dans les inscriptions ptolémaïques de Philae (H. JunKer et E. WinTER, Das Geburtshaus des Tempels der Isis in Philä, Vienne, 1965, p. 170-171, photo 891, dans la légende de Sothis). Cette variante du signe U97A, telle qu'on peut la voir à Philae, montre une forte ressemblance avec le signe présent dans le Décret et note le toponyme $H h t$. Toutefois, Wb. III, p. 67, atteste une variante (au signe Aa5 notant $h p$ ) d'époque gréco-romaine qui ressemble au signe présent dans le Décret et concorde avec l'interprétation de Junker, mais la graphie indiquée $\wedge$ suppose que le sculpteur ait gravé par erreur ce signe dans le sens inverse au sens de lecture du Décret, ce qui amoindrit la validité de cette hypothèse. De plus, nous n'avons trouvé aucune autre attestation ou mention d'un toponyme Hpt que celle présentée par JUNKER, p. 3. Or, en Wb. III, p. 331, 1213 , il est fait mention d'un toponyme $H h t$ formé sur le mot $h h$, «égaliser ». D’après WILSON, p. 748, le terme hh " peser » est attesté dans le toponyme hht identifié à Éléphantine. Selon H. GAUTHIER, Dictionnaire des noms géographiques contenus dans les textes hiéroglyphiques IV, Paris, 1931, p. 186-187, Hht est une « désignation tardive de la ville d’Éléphantine (métropole du $\mathrm{I}^{\mathrm{er}}$ nome de Haute-Égypte), aujourd'hui Geziret-Assouan ». H. BRUGSCH, Dictionnaire géographique de l'ancienne Egypte, Leipzig, 1879, p. 628, indique que $H h t$ signifie «la ville de l'équilibre », c’est-à-dire l'équilibre cosmique rétabli par la déesse Sothis lors de son lever héliaque, et désigne la ville de Syène (Assouan) ou l'île d'Éléphantine en face de Syène. Satis est «maîtresse d'Éléphantine » $(H h t)$ dans les inscriptions du temple de Biggeh. Nous proposons que cette phrase lie sémantiquement le dieu Khnoum qu'évoque le bélier du signe $b$ ว et le toponyme $H h t$ dont la 
Ba vénérable est ton nom dans la Butte pure. Phénix divin (2) est ton nom dans Biggeh. Ba puissant est ton nom dans le temple de Sekhmet. Ba à la forme efficace ${ }^{79}$ est ton nom dans Philae. Ba pleuré est ton nom dans le temple d'Isis ${ }^{80}$. Ba vivant est ton nom dans Éléphantine ${ }^{81}$. Tu es ${ }^{(3)}$ le ba qui est supérieur au ba des dieux ${ }^{82}$.

\section{L'accueil du Ba d'Osiris sur l'Abaton}

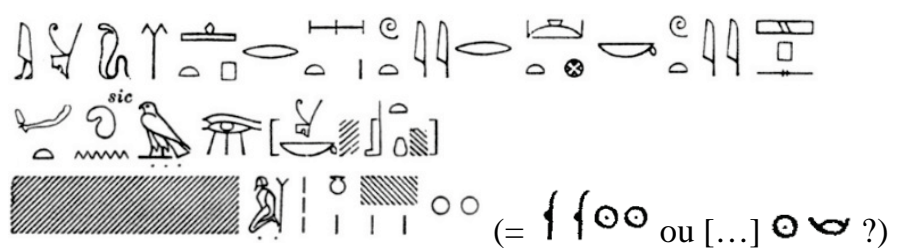

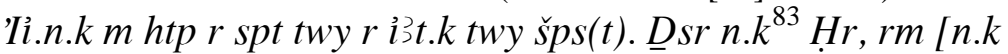
3st ...] sbiw/šntyw ${ }^{84} m^{!}[\text {trwy? }]^{85}$.

Tu es venu ${ }^{86}$ en paix sur ce territoire, sur cette butte vénérable qui est tienne. C'est à toi qu'Horus (la) consacre ${ }^{87}$, [c'est sur toi qu'Isis] pleure. [...] les ennemis [pour toujours? ${ }^{38}$.

« maîtresse » n’est autre que sa parèdre Sothis-Satet dans les textes de Philae et de Biggeh.

${ }^{78}$ Valeur $b$ ว du signe J339 dans DAUMAs, p. 372. Il s’agit de la seule occurrence de la lecture $b$ ว pour le signe J339, proposée dans JUNKER, p. 5.

${ }^{79}$ Le Ba du dieu est dit « à la forme efficace » car sa forme (îrw), la statue habitée par le Ba divin, prodigue au roi protection et soutien en échange du culte qui lui est rendu. Pour la signification de l'expression spd irw, voir WILSON, p. 833.

${ }^{80}$ Il s'agit du grand temple d'Isis à Philae.

${ }^{81}$ JUNKER : hpt ; ROEDER : Elephantine.

${ }^{82}$ ROEDER : Du bist der Falke, der oberste (Herr) der Falkenweibchen (?).

${ }^{83}$ Les signes $n$ et $k$ sont inversés pour des raisons esthétiques. Le phénomène de l'inversion est fréquent dans cette inscription.

${ }^{84}$ La graphie concernée est propre à l'écriture ptolémaïque, ce qui nous permet de distinguer deux possibilités de lecture (sbiw/šntyw) et d'écarter les paronymes (hftyw entre autres). Quelle que soit la lecture du signe, le sens est clair : il s'agit des "ennemis » du dieu. Voir Wb. IV, p. 87 (14) pour sbiw ; Wb. IV, p. 520 (4-5) pour šntyw.

85 trwy : les deux temps, c'est-à-dire, le jour et la nuit, toujours. Voir $W b$. V, p. 316 (1-2). Le $n$ remplace souvent le $m$ en ptolémaïque pour des raisons phonétiques : voir $\mathrm{H}$. W. FAIRMAN, « An Introduction to the Study of Ptolemaic Signs and their Values », dans BIFAO 43 (1945), p. 64. On pourrait également lire avec le même sens, mais sans expliquer la lacune, $n$ [...] $r^{c} n b$.

${ }^{86}$ JUNKER et ROEDER : Du kommst.

${ }^{87}$ JUNKER : Horus ist (macht) dir diśr (?) ; ROEDER : Horus richtet sie dir schön her. Usage transitif du verbe $\underline{d} s r$, « être sacré ». Ce développement du verbe $\underline{d} s r$ s'est produit à la période tardive, en accord avec l'extension de sens d'autres verbes intransitifs comparables. Ce phénomène apparaît à Edfou, comme une alternative à $s \underline{d} s r$, et dans les temples gréco-romains. Pour le verbe $\underline{d} s r$, dont le sens premier est « rendre sacré, consacrer », voir Wb. V, 613 (19), Wilson, p. 1247, Junker, p. 36. Cette occurrence du verbe $\underline{d} s r$ implique également l’idée de « rendre inaccessible aux profanes ». 
La glorification d'Osiris sur l'Abaton

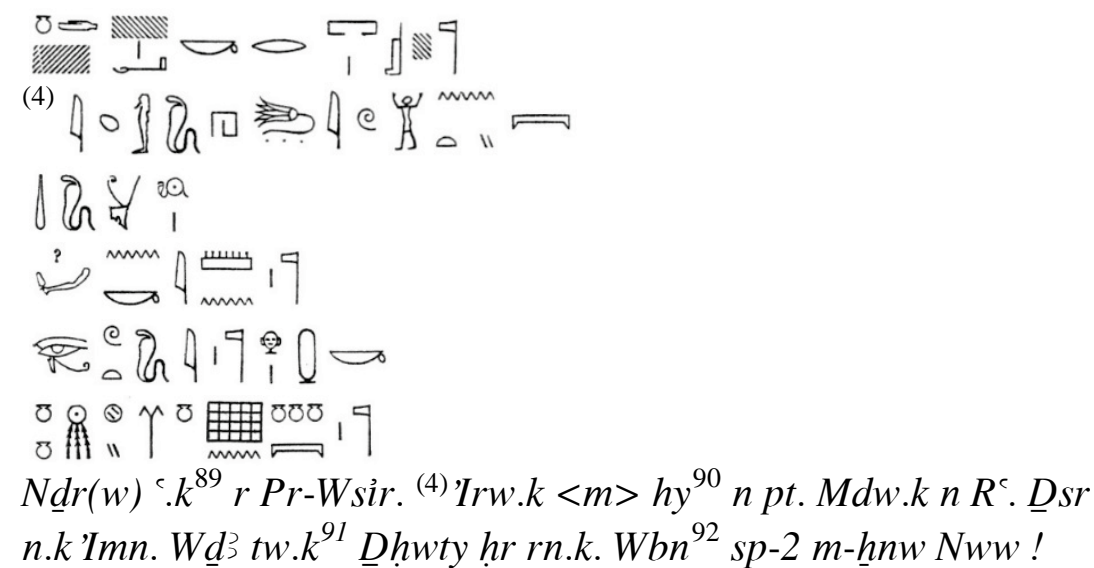

Ta personne est conduite vers le temple d'Osiris ${ }^{93}$. ${ }^{(4)}$ Ta forme se réjouit jusqu'au ciel. Tu t'adresses à Rê. Amon ${ }^{94}$ te sanctifie. Thot te rend prospère en ton nom ${ }^{95}$. Resplendis dans le Noun, ô toi resplendissant ${ }^{96}$ !

En ce sens, voir Wb. V, 614 (14) et J.-C. GoYon, Les Dieux-Gardiens et la Genèse des Temples (BdÉ 92), Le Caire, 1985, p. 274.

${ }^{88}$ JUNKER : ... die Feinde des ... immerdar (?); ROEDER : [Harendotes und Arsnuphis töten deine] Feinde in Ewigkeit. La restitution de Roeder est fondée sur la présence d'Harendotes et d'Arensnouphis en tant que dieux tuant les ennemis d'Osiris dans une scène de la Porte d'Hadrien et dans les textes des Mystères. Voir JunKER, p. 6.

${ }^{89}$ D'après WiLson, p. 568-569, le verbe $n \underline{d} r$ peut signifier « to hold, to seize ». Voir aussi Wb. II, p. 383 (3). Par ailleurs, le substantif ‘, «bras », peut avoir le sens de «corps, personne ». La forme de la «personne» () divine d'Osiris est désignée par le terme irw mentionné plus haut. En outre, on observe une inversion entre le trait de l'idéogramme et le signe du bras.

${ }^{90}$ Voir Wb. II, p. 483. Voir Ch. LEITZ, Quellentexte zur ägyptischen Religion I : Die Tempelinschriften der griechisch-römischen Zeit, Berlin, 2009, p. 48. Un $w$ final parasite est fréquent en ptolémaïque. Voir H. JUNKER, Grammatik der Denderatexte, Leipzig, 1906, § 20.

${ }^{91}$ Pronom objet de la deuxième personne du singulier. Voir H. JUNKER, Grammatik der Denderatexte, Leipzig, 1906, § 52.

${ }^{92}$ Valeur wbn du signe W523 dans DAUMAS, p. 805.

${ }^{93}$ C'est-à-dire le sanctuaire du dieu à Biggeh.

94 "Amon qui réside à l'Abaton » ('Imn-R $R^{c} h r y$-ỉb 'T3t $w^{c} b t$ ) est mentionné dans une scène du mammisi de Philae datant de Ptolémée VIII Évergète II (145-116). Voir G. ZAKI, Le Premier Nome de Haute-Égypte du IIIe siècle avant J.-C. au VII siècle après J.-C., Turnhout, 2009, p. 134, doc. $\mathrm{n}^{\circ} 53$; H. JUNKER et E. WinTER, Das Geburtshaus des Tempels der Isis in Philä II, p. 72-73, photo 936 .

${ }^{95}$ Thot, le dieu des connaissances religieuses, rend prospère Osiris « en son nom ", c'est-à-dire soit par référence à une épiclèse divine d'Osiris exprimant sa nature pérenne dans une légende de la Porte d'Hadrien, soit plus probablement au moyen de formules rituelles. Voir Wb. II, p. 427 (7-8).

${ }^{96}$ ROEDER : Re erläßt einen Befehl für dich, Amon richtet ihn dir schön her, Thot ruft dich an (?) auf deinen Namen, der du aufgingst im Nun! Il semble que Roeder ait surinterprété ce passage. Pour la fin du passage, JunKER : Erglänze aus dem Ozean, du Glänzender. Le texte du décret fait ici référence au premier lever de Rê à partir du Noun au moment de la création et renvoie donc à l'entité divine Osiris-Rê. En effet, chaque nuit, Rê vient 


\section{1b. Le décret stricto sensu}

\section{Introduction}

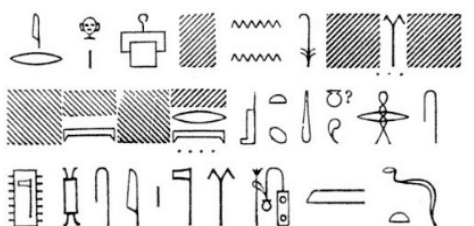

Ir hr-s’ $[\ldots] n n[\ldots r]$ วst $m d w . s^{97} h n^{\varsigma} . s, n t r . n^{98} s(y)$ Dhhwty $m s \check{s}$ $m \underline{d} d$ :

C'est pourquoi [...] Isis [...] une parole qui la concerne ${ }^{99}$ et Thot l'a rendue pure ${ }^{100}$ dans ses écrits en ces termes :

Les termes du décret

(5)

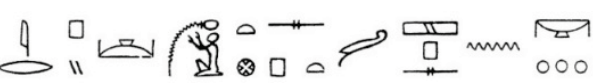

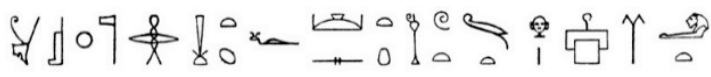

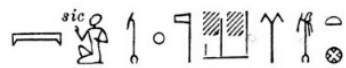

(5) 'Ir $p$ (3)y 'İt w'bt, spt šps n(y) nbw n(y) Wsir hhn snt.f 3st,

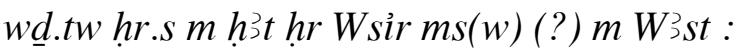

(5) «Concernant la Butte pure, le saint territoire d'or ${ }^{101}$ d'Osiris et de sa sœur Isis, il a été décrété à son sujet, dès le commencement, au profit d'Osiris qui avait été enfanté (?) à Thèbes $^{102}$ :

s’unir à Osiris dans le monde souterrain de l'Au-delà afin de se régénérer avant d'apparaître de nouveau à l'horizon.

${ }^{97}$ Valeur $s$ du signe G649 dans DAUMAS, p. 286.

${ }^{98}$ Valeur $n$ du signe T177 dans DAUMAS, p. 664.

99 Le pronom désigne la Butte pure. JUNKER : ... [-Stätte ...] Isis ... spricht mit ihr ?; ROEDER : ... die Stätte, und Isis ... einen wohltätigen Befehl in bezug auf sie (?). Le verbe devant logiquement se trouver en tête de phrase dans la lacune, nous suivons Roeder, tout en traduisant plus littéralement.

${ }^{100} n t r$, « purifier », est la forme transitive de $n \underline{t} r i$, « être pur ». Voir WILson, p. 560. Dans les inscriptions de Biggeh, Thot est le dieu « qui purifie tout ». Par ailleurs, ces inscriptions insistent de façon assez marquée sur la pureté du temple, des membres du dieu et des prêtres. Voir A. M. BLACKMAN, The temple of Bîgeh (Les Temples immergés de la Nubie), Le Caire, 1915, p. 45 et 47.

${ }^{101}$ Ce saint territoire est «d'or » car il est divin tout comme la butte de la création divinisée sous le nom de Tatenen et assimilée au démiurge. Dans les cosmogonies, les démiurges s'éteignent après leur acte créateur pour reposer dans des buttes. Rappelons également que la chair des dieux est faite d'or ; de plus, la figurine d'orge et de terre d'Osiris se change symboliquement en or et la « salle de l'or » est le lieu de la divinisation du pharaon dans sa tombe. La divinisation de l'Abaton renforce son caractère inaltérable qu'évoquent également les roches granitiques de l'île, pierres d'éternité.

102 L'enfance d'Osiris à Thèbes, l'une des grandes villes religieuses d'Égypte, est attestée notamment chez Plutarque (De Iside et Osiride, 12) qui raconte que l'enfant fut confié à un certain Pamylès à Thèbes. En revanche, Plutarque ne dit pas qu'Osiris y est né. 


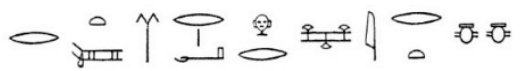

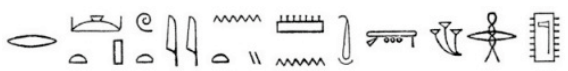

(6)

$$
\triangle 44 \times 5 . j \circ \Longrightarrow
$$

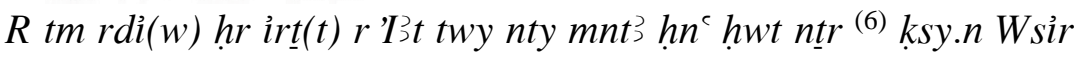
im.s.

On ne permettra pas que $e^{103}$ le lait fasse défaut à cette butte où se trouvent le bosquet-mnt3 et le temple ${ }^{\left({ }^{(6)}\right.}$ dans lequel Osiris est inhumé $e^{104}$.

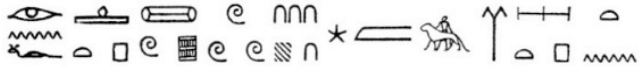

$$
\begin{aligned}
& 4 \text { की एक }
\end{aligned}
$$

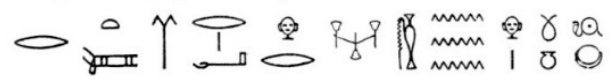

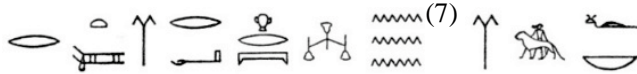

Ir n.f htpw $365 \mathrm{~m}$ phr $m$ spt tn, iw kbw n(y)w bn(i)w ${ }^{105}$ hr.sn.

$R$ tm rdi(w) hr kbhww hr.sn $r^{c} n b, r$ tm rdi(w) hr mw ${ }^{(7)} m-p h r . f$ $n b$.

On dressera pour lui 365 tables d'offrande autour de ce territoire, tandis que des feuilles de palme seront disposées sur celles-ci. On ne permettra pas que les libations ${ }^{106}$ sur celles-ci viennent à manquer aucun jour, on ne permettra pas que l'eau vienne à manquer ${ }^{(7)}$ tout autour de ce territoire.

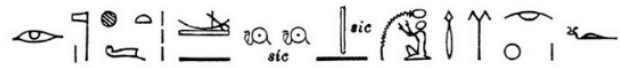

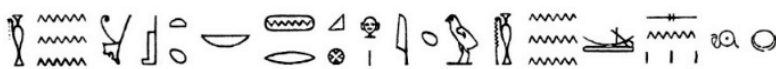

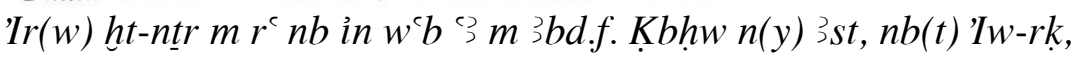
hr ir $(t)$ kbhw im.sn $r^{c} n b$.

Le rituel divin sera accompli chaque jour par le grand-prêtre, qui effectue son office mensuel. Le choachyte ${ }^{107}$ d'Isis, dame de Philae, accomplira la libation sur celles-ci chaque jour.

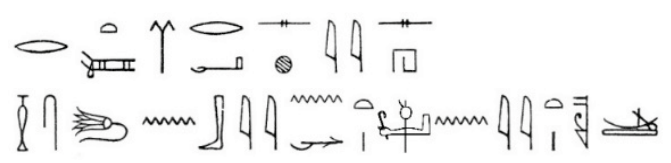

\footnotetext{
${ }^{103}$ Littéralement : Pour ne pas permettre que...

104 JUNKER : an dieser Stätte auf der der mnt’-Hain und das Heiligtum, in dem Osiris begraben wird, liegt ; ROEDER : an dieser Stätte, auf welcher der Mente-Baum und der heilige Begräbnisplatz des Osiris sich befinden; YOYOTTE: à cette butte de l'arbre-mentè ni à (ce) temple où Osiris est inhumé.

${ }^{105}$ Voir Wb. I, p. 461 (12) : bnr ou bni.

${ }^{106}$ ROEDER : die Flüssigkeit.

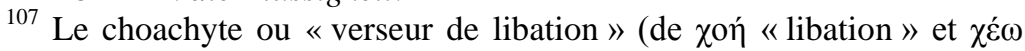
« verser ») est le terme grec correspondant à l'égyptien $k b h w$ qui désigne les prêtres spécialement chargés de faire les libations pour les morts. Voir J. YOYOTTE, P. CHARVET et S. GOMPERTZ, op. cit., p. 261.
} 
$R$ tm rdi(w) shy sh(r) hisi $n$ bynt wdnyt ${ }^{108}$.

On ne permettra pas de battre du tambourin et de jouer de la harpe ou du hautbois ${ }^{109}$.

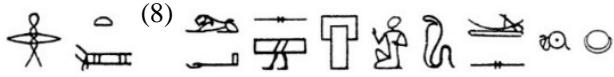

$$
\begin{aligned}
& \frac{8}{x} \gamma_{0}^{0}=0
\end{aligned}
$$

Et on ne permettra ${ }^{(8)}$ à aucun homme d'y passer quel que soit le jour, et on ne permettra pas [au grand et] au petit ${ }^{111} d^{\prime} y$ passer.

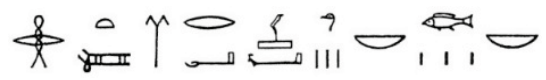

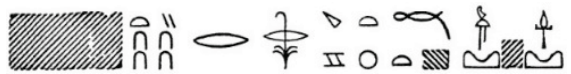

$H n^{c}$ tm rdi(w) grg 3pdw nbw rmw nbw [...] 40 r Rsyw, Mhty, 'Imtt, 'I3bt.

Et on ne permettra de capturer aucun oiseau ni aucun poisson (sur une distance de) $[x+] 40$ (coudées) vers le Sud, le Nord, l'Ouest et l'Est.

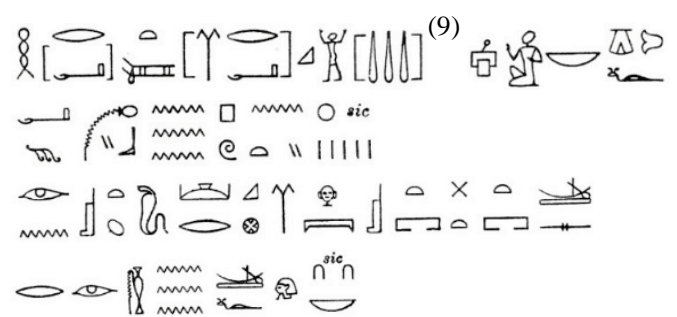

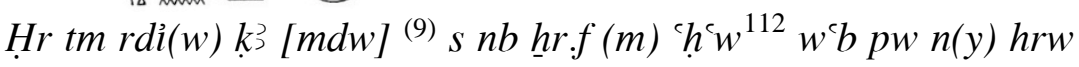
ir(w).n.f зst, nbt 'Iw-rk, $m$ hrr(yt) st wrt im.s $r$ ir(t) kbḥw im.f $h r^{113} h r w^{114} 10 n b$.

${ }^{108}$ Le signe V25 (corde enroulée sur un bâton) est en combinaison avec le signe D40 (bras tenant un bâton) et forme un monogramme lu $w \underline{d}$ comme le signe simple V25. Or, comme le note S. EMERIT, « À propos de l’origine des interdits musicaux dans l'Égypte ancienne », dans BIFAO 102 (2002), p. 190, n. 8, le signe D40 est manquant dans le relevé de l'inscription chez JunKER, p. 21, n 42 . Nous avons donc modifié le relevé de H. Junker à cet endroit dans notre copie.

109 Selon S. Emerit, le terme $w \underline{d} n y t$ désigne un double hautbois. Voir S. EMERIT, « À propos de l'origine des interdits musicaux dans l'Égypte ancienne », dans BIFAO 102 (2002), p. 199. Pour ḩsi + un instrument de musique dans le sens de « jouer d'un instrument », voir IDEM, p. 205.

${ }^{110}$ Les deux im.s renvoient à ' $3 t w^{`} b t$.

111 JUNKER : und es darf kein (Hoher ? oder) Niedriger sie betreten; ROEDER : und daß [Laien und] Bürger es betreten. Roeder imagine ainsi que ce passage devait préciser que l'interdiction de fouler le sol de l'Abaton était valable aussi bien pour les profanes en pèlerinage à Philae que pour les habitants de la région. Toutefois, il est plus probable que ce passage étende l'interdiction aux hommes riches et influents comme aux hommes de condition modeste.

${ }^{112}$ Voir Wb. I, p. 222-223. 
Et on ne permettra d'élever la voix ${ }^{(9)}$ en contrebas ${ }^{115}$ à aucun homme durant la période pure des jours qu'Isis, dame de Philae, y passe, en tant que celle qui est sur le Trône ${ }^{116}$, afin d'accomplir alors ${ }^{117}$ une libation tous les dix jours.

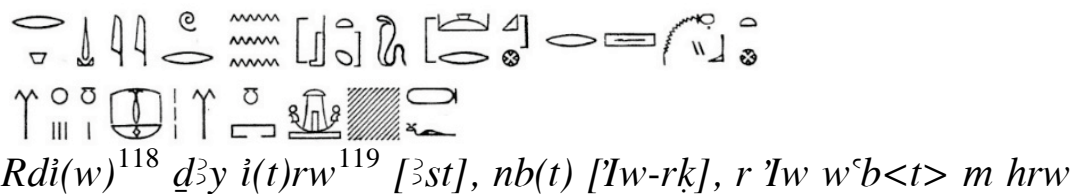
$n(y) w$ hbw $m$-hnhw wỉ, [Gsdp? $]^{120}$ rn.f.

On fera en sorte qu'Isis, dame de Philae, traverse le fleuve jusqu'à l'T̂le pure lors des jours de fête $e^{121}$, à bord de la barque nommée Gesdep (?).

\section{1c. La rédaction divine du décret}

(10)

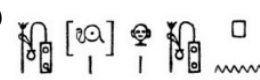

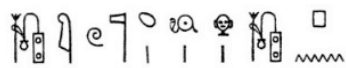

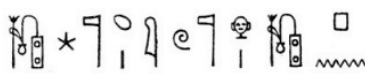

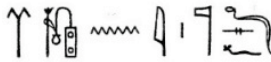

${ }^{(10)} S \check{s} R^{`} h r s \check{s} p n, s \check{s} \breve{S} w, s^{3} R^{`}, h r s \check{s} p n, s \check{s} G b, s^{3} \check{S} w, h r s \check{s} p n$, $m s \check{s} n(y) \underline{D} h w t y \underline{d}$ s.f.

${ }^{(10)}$ Rê a signé cet écrit, Shou ${ }^{122}$, fils de Rê, a signé cet écrit (et) Geb, fils de Shou, a signé cet écrit sur l'écrit de Thot luimême $e^{123} »$.

\footnotetext{
${ }^{113}$ Valeur $h r$ du signe E3 dans DAUMAS, p. 143.

${ }^{114}$ Le Décret II fournit une variante permettant de corriger le premier signe 10 par hrw. Voir JUNKER, p. 23.

${ }^{115}$ Cette expression s'accorde bien avec le relief marqué de la Butte sacrée.

${ }^{116}$ Le «Trône » désigne le Saint des Saints du temple de Biggeh où s’installait la statue de la déesse Isis lorsqu'elle venait rendre hommage à son époux.

${ }^{117}$ Complément de temps équivalent à durant cette période.

${ }^{118}$ Valeur di du signe W143 dans DAUMAS, p. 777.

${ }^{119}$ Sur $\underline{d}^{3}$ i itrw, voir $W b . \mathrm{V}, \mathrm{p} .512$ (11).

${ }^{120}$ Restitution de JUNKER, p. 28, d'après la ligne 12 du Décret II.

${ }^{121}$ YOYOTTE : lors des trois jours de fête.

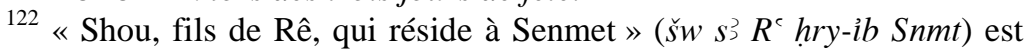
mentionné dans une scène du Mammisi de Philae. Voir G. ZAKI, op.cit., p. 136, doc. n54 ; H. JUNKER et E. WINTER, Das Geburtshaus des Tempels der Isis in Philä II, p. 74-75, photo 938.

123 JUNKER : (es ist) von Thot selbst geschrieben. Le décret est présenté comme une décision de Rê, le dieu suprême, en faveur d'Osiris, le dieu assassiné et devenu maître de l'Au-delà. Ce document, contresigné par les successeurs de Rê sur son trône, le dieu de l'air Shou et le dieu de la terre 


\section{Les reliefs de la Porte d'Hadrien}

\section{2a. Les représentations du mur nord}

\section{La source du Nil et le Ba d'Osiris}

Dans l'angle gauche du mur nord figure l'île de Biggeh. L'on y observe, posés au-dessus des rochers, un vautour et un faucon qui représentent Isis et Horus.

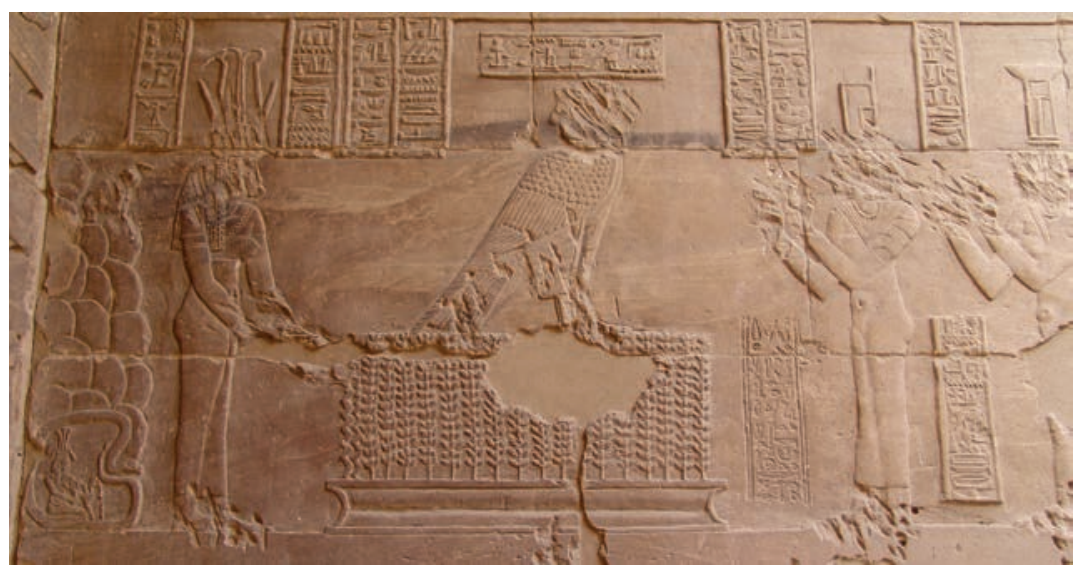

Fig. 7. La source du Nil et le Ba d’Osiris

Cette figuration de la caverne du Nil constitue une image mythique et imaginaire de l'Abaton qui a l'apparence d'une caverne $(t p h t)$ creusée au pied d'une falaise. Elle enferme en son sein, dans les contours circulaires d'un serpent, le Nil fécondateur, le génie Hâpy, assimilé à Osiris, qui déverse symboliquement l'inondation à l'aide de vases à libation.

Devant la caverne, Hathor-Isis, à tête de vache, verse une libation sur le bosquet sur lequel est posé le Ba d'Osiris. Les rochers de l'île renferment la tombe du dieu qui est décrite en légende comme "celle qui est dissimulée et cachée, la haute colline $\left(\underline{d} w k_{3}\right)$ dans Biggeh $(S n m t){ }^{124}$. Nous reviendrons sur le reste de la scène dans l'examen du texte de Claudien.

Geb, et rédigé par Thot lui-même, nous apprend que l'Abaton était dédié au silence et au calme, étant consacré à Osiris et voué à son sommeil éternel. $\mathrm{Au}$ niveau de la structure, les recommandations positives (libations, rites à accomplir) précèdent les recommandations négatives (multiples interdictions) du décret.

${ }^{124}$ S. CAUVIlle, M. IBrahim Ali, Phila : Itinéraire du visiteur, Louvain, 2013, p. 267. 


\section{Les dieux garants du décret}

Les dieux représentés à droite sont, de gauche à droite, Isis et Nephtys, Rê-Horakhty et Amon.

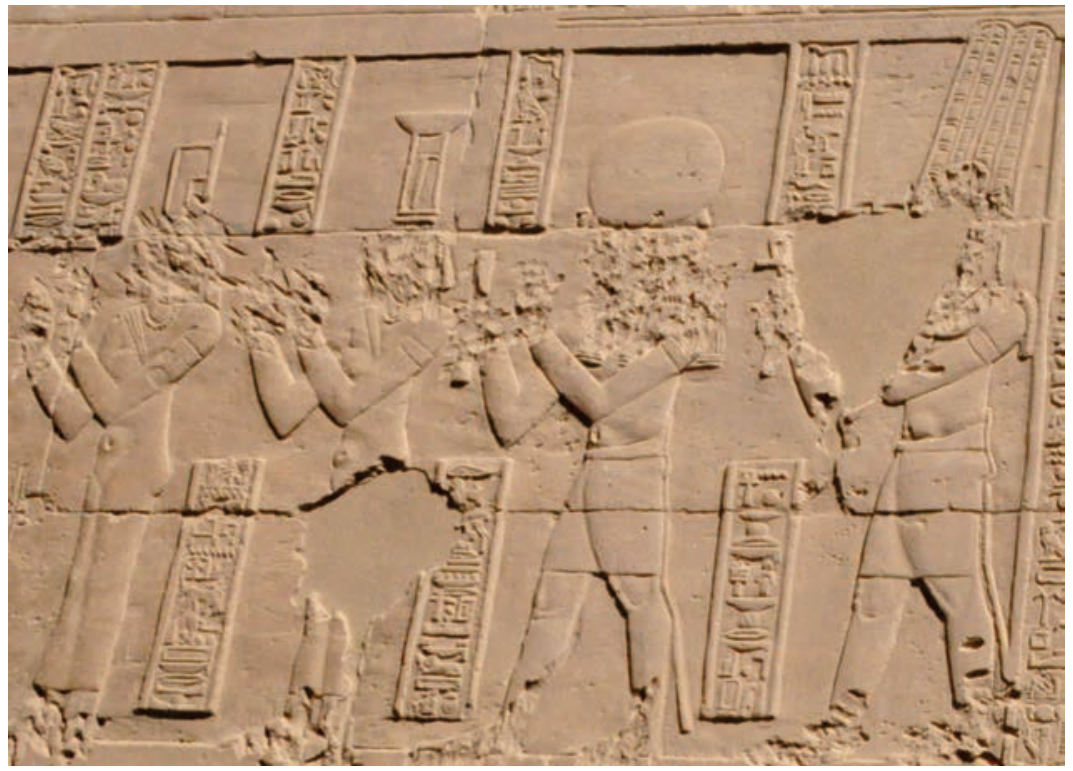

Fig. 8. Les dieux garants du décret

Rê-Horakhty tient en main l'étui- $m k s^{125}$, tandis qu'Amon tend à Osiris le signe de vie. Dans la légende, Rê-Horakhty s'adresse à Osiris : " Je fais pour toi un décret valable dans tout le pays, concernant ta nécropole sacrée dans la Butte pure » ${ }^{126}$.

\section{2b. Les représentations du mur sud}

Le relief d'Osiris dans le bosquet mnt’ (côté gauche)

Osiris est présenté en gloire, entouré d'Isis et de Nephtys en adoration (fig. 9). La scène évoque le bosquet $m n t$ ’ , dans lequel Osiris se fond complètement, et le canal proche de l'Abaton par le biais du signe hiéroglyphique du canal gravé sous les pieds du dieu. Ce relief offre donc une information topographique des plus précieuses : le bosquet $m n t^{3}$ prospérait le long d'un canal. En effet, bien que les textes rassemblés dans cette étude ne donnent que peu de données quant à la localisation précise du bosquet sacré, une formule plus explicite de Philae évoque devant Osiris de Shenâ-khen, la butte sacrée du $21^{\mathrm{e}}$ nome de Haute-Égypte, «les arbres (qui) verdoient à l'orifice de son Abîme $(d w 3 t) » 127$.

\footnotetext{
${ }^{125}$ Il s'agit d'un étui cylindrique contenant les actes établissant la légitimité du roi, en l'occurrence Rê. Voir É. Drioton, Pages d'Égyptologie, Le Caire, 1957, p. 311.

126 S. CAUVILLE, M. IBRAHIM Ali, op. cit., p. 267.

127 J. YoyotTE, «Études géographiques I. La « Cité des Acacias » (Kafr Ammar) », dans $R d E ́ 13$ (1961), p. 100 : la $d w^{3} t$ mentionnée fait référence à un « abîme souterrain, identique ou comparable à la grande $D w 3 t$ cosmique
} 


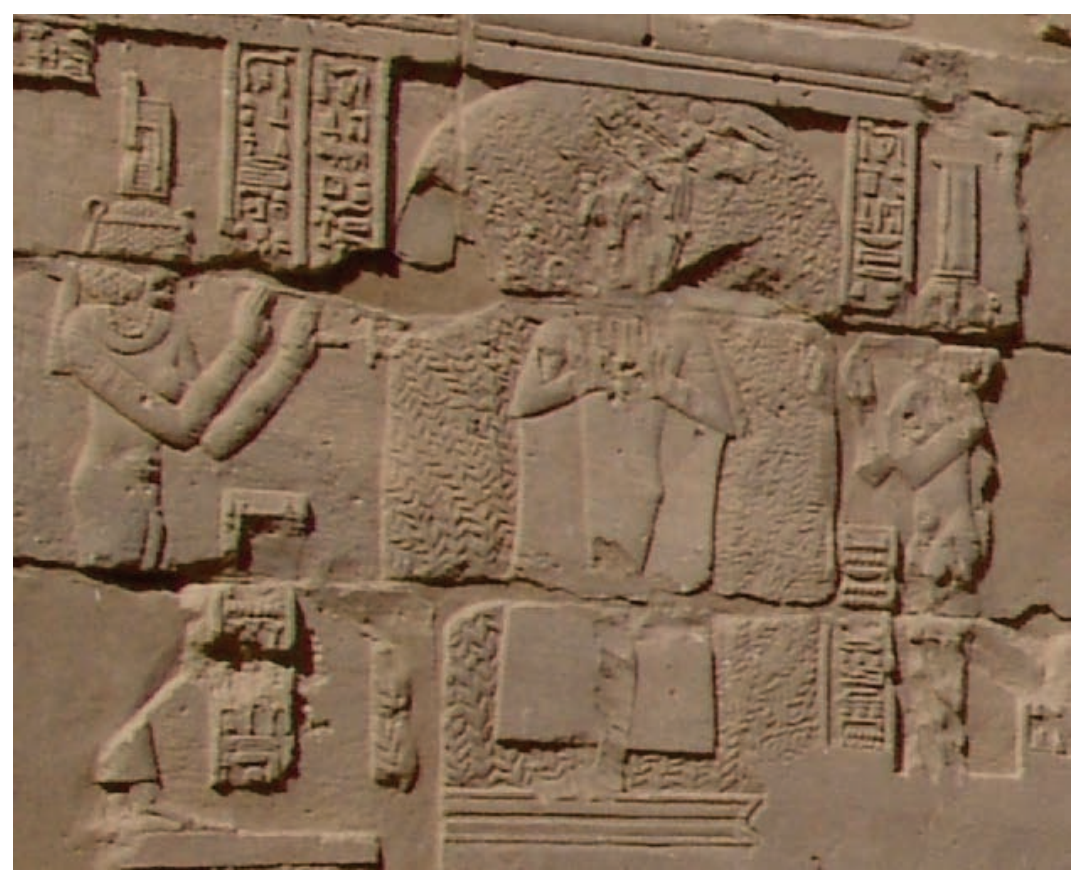

Fig. 9. Le relief d’Osiris dans le bosquet $m n t^{3}$

Le bosquet sacré devait verdoyer tout autour du temple d'Osiris contenant la sépulture du dieu. Il est clair également que le bois avait pour fonction non seulement de protéger la tombe d'Osiris ${ }^{128}$, mais aussi de marquer une séparation entre mondes divin et humain, entre sacré et profane, en dissimulant la sépulture dans la "colline » derrière un mur de verdure. Dans son ensemble, il symbolisait la renaissance perpétuelle d'Osiris.

Le transport de la momie d'Osiris vers Biggeh

(côté droit, au-dessus de l'embrasure de la porte)

Durant la nuit, Osiris, sous la forme d'une momie, est transporté par un crocodile ${ }^{129}$ à tête de faucon (Horus) de l'autre côté du Nil, vers l’île de Biggeh illustrée par les rochers. Osiris,

qui existait sous notre monde et d'où montait la force du Nil », c'est-à-dire le monde souterrain des morts, royaume d'Osiris.

${ }^{128}$ Cette protection naturelle est renforcée par la garde protectrice des dieux morts qui veillaient sur leur ancêtre Osiris. Isis et Nephtys échangeaient parfois cette tâche avec les deux déesses locales Satis et Anoukis, ce qui témoigne de la popularité de la triade d’Éléphantine dans la région et à Biggeh. Voir G. ZAKI, op. cit., p. 196 et D. VALBELLE, Satis et Anoukis (SDAIK 8), Mayence, 1981, p. 141. Onze puissants génies à tête de chien, de bélier, d'homme ou de faucon, sont présents dans les représentations du temple de Biggeh. Armés de couteaux, ils incarnent une protection supplémentaire. Voir A. M. BLACKMAN, The temple of Bîgeh (Les Temples immergés de la Nubie), Le Caire, 1915, p. 33-34.

${ }^{129}$ Horus est assimilé à Sobek d’Ombos, chargé dans la théologie locale du rapatriement du corps d'Osiris. Voir G. ZAKI, « Sobek et le rapatriement d'Osiris à ' $t$-'3t à l'époque romaine », dans Göttinger Miszellen 188 (2002), p. 103-108. 
assis sur un trône, est identifié avec le soleil ${ }^{130}$, Horus l'enfant étant à ses côtés. La double colline de l'horizon évoque le paysage de Biggeh. Isis se tient à gauche comme si elle venait de Philae rendre hommage à son époux défunt ${ }^{131}$. Des plants de papyrus occupent le bas de la scène et font songer à un endroit marécageux aux abords du Nil. Ces fourrés de papyrus peuvent renvoyer soit à la nature marécageuse de la rive orientale de Biggeh à l'époque, attestée chez Servius (cf. infra), soit à l'origine de cet épisode des Mystères d'Osiris qui se déroulait dans le Delta ${ }^{132}$.

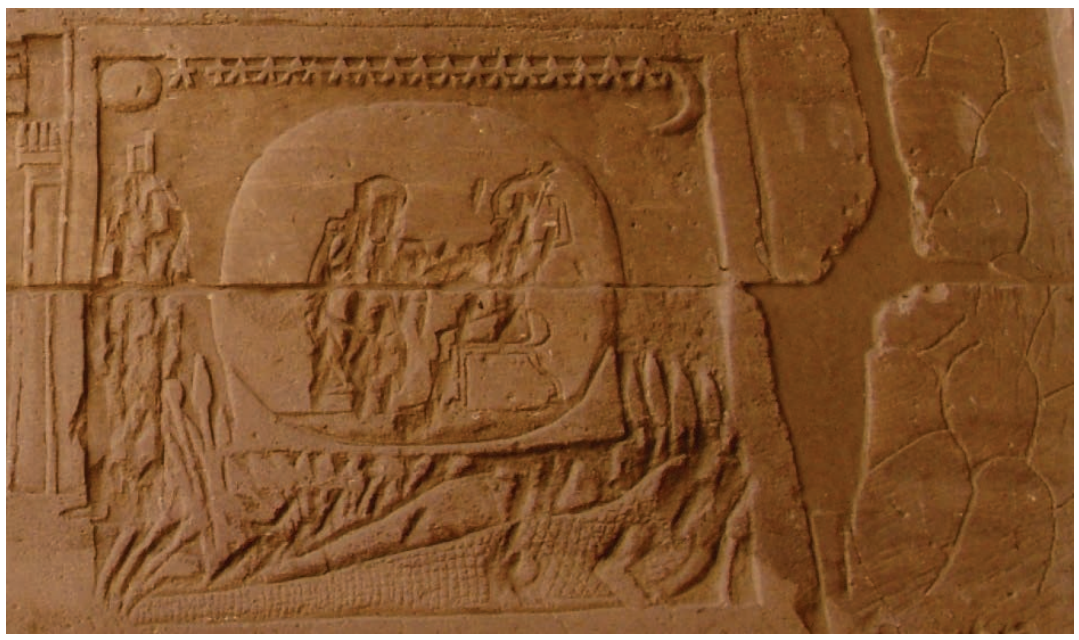

Fig. 10. Le transport de la momie d’Osiris vers Biggeh

Après examen, les textes et les reliefs de la Porte d'Hadrien à Philae démontrent donc l'étroite relation théologique et iconographique qui unit Philae et Biggeh.

\section{Un relief du temple d'Hibis à Khargeh}

L'île de Biggeh abritait une relique ${ }^{133}$, la jambe gauche d'Osiris, appelée nh] in sỉsty et surnommée «la Grande-

\footnotetext{
${ }^{130}$ Le sycomore, établi sur le tertre de l'Abaton et assimilé à Osiris, est justement lié à la naissance du soleil.

${ }^{131}$ Notons que la disposition du mur respecte la géographie environnante : Biggeh devait se trouver vers la droite, comme les rochers suggérés sur la droite de la représentation, dans l'angle ouest.

${ }^{132}$ S. CAUVILLE, M. IBRAHIM Ali, Philce : Itinéraire du visiteur, Louvain, 2013, p. 272.

${ }^{133}$ Sur la relique de Biggeh, voir É. CHASSINAT, Le mystère d'Osiris au mois de Khoïak, Le Caire, 1966, p. 153 et 375 ; D. VALBELlE, Satis et Anoukis (SDAIK 8), Mayence, 1981, p. 62, n³02 ; H. BEINLICH, Die Osirisreliquien: zum Motiv der Körperzergliederung in der altägyptischen Religion (Ägyptologische Abhandlungen 42), Wiesbaden, 1984, p. 209-210. Sur les reliques d'Osiris dans leur ensemble, voir L. CouLON, « Les reliques d’Osiris en Égypte ancienne: données générales et particularismes thébains ", dans P. BORGEAUD et Y. VOLKhINE, Les objets de la mémoire : pour une approche comparatiste des reliques et de leur culte (Studia religiosa Helvetica 10-11), Berne, 2005, p. 15-46.
} 
Noble » $(s r t-w r t)^{134}$. Une représentation de la relique de Biggeh sous la forme du reliquaire abydénien se trouve au temple d'Hibis à l'oasis de Khargah dans le désert occidental (fig. 11).

Le reliquaire surmonte la « Haute colline » (Fig. 7) sise sur le signe de l'or $\sqrt{\infty}$ mon , le territoire de l'Abaton étant «d'or » ${ }^{135}$. Par les vertus de cette relique, lors de la crue annuelle, les eaux du Nil jaillissaient à foison pour fertiliser les villes de Thébaïde et toute la Haute-Égypte ${ }^{136}$. Sur la droite de l'image ci-dessous se dresse un magnifique faucon orné de la double couronne royale, qui représente Horus, à queue de crocodile ${ }^{137}$, ce qui témoigne de l'implication d'Horus dans l'enterrement de son père et la protection de sa dépouille comme dans le relief précédent visible à Philae.

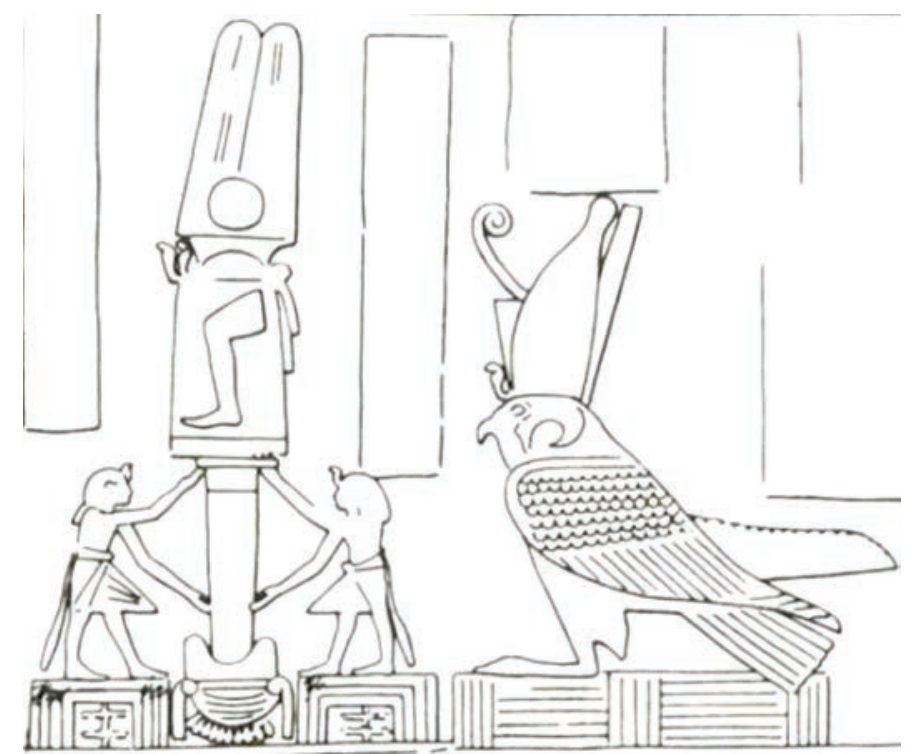

Fig. 11. Relief du temple d'Hibis

(N. DE GARIS DAVIES, The Temple of Hibis in El-Khargeh Oasis. Part III : The Decoration, New York, 1953, planche IV.1)

En outre, l'Abaton est en connexion avec le lieu caché, l'abîme $\left(d w^{3} t\right)$, d'où monte l'inondation, issue des lymphes $(r \underline{d} w)$ du cadavre d'Osiris ${ }^{138}$. La jambe gauche est cachée dans une $d w^{3} t$ : Isis remonte vers l'Abaton, elle pénètre dans le gouffre de l'abîme ( $d w^{3}$ t) et y trouve les deux jambes d'Osiris

${ }^{134}$ Voir Wb. IV, p. 32 (7). On trouve aussi simplement « la jambe » ( $\left.w^{c} r t\right)$. Voir G. ZAKI, Le Premier Nome de Haute-Égypte, Turnhout, 2009, p. 227.

${ }^{135}$ Voir Décret I, col. 5 : le saint territoire d'or d'Osiris et de sa sœur Isis. Le signe de l'or est fréquemment utilisé dans le temple de Biggeh sous des déesses ou des cartouches. Voir A. M. BlackMAn, The temple of Bîgeh (Les Temples immergés de la Nubie), Le Caire, 1915, planche XXIV.

136 J. YoyotTE, «Études géographiques I. La « Cité des Acacias » (Kafr Ammar) ", dans RdÉ 13 (1961), p. 102. JUNKER, p. 27-41.

${ }^{137}$ Voir G. ZAKI, op. cit., p. 219.

138 J. YOYOTTE, loc. cit., p. 102 ; JUNKER, p. 37-40. 
en action ${ }^{139}$. Un relief de Philae figurant la relique de Biggeh montre le bassin et les membres inférieurs du dieu; l'eau qui jaillit de la cuisse gauche est recueillie par Isis et Nephthys ${ }^{140}$. Shenâ-khen (Acanthôn) conserve aussi la jambe gauche ${ }^{141}$.

\section{Les sources classiques}

\section{A. DIODORE DE SICILE, Bibliothèque historique, I, 22}

Le témoignage de Diodore, qui date du $\mathrm{I}^{\mathrm{er}}$ siècle avant notre ère, est le texte classique le plus ancien conservé sur l'Abaton de Biggeh. L'auteur tire ses informations de témoignages oraux ou écrits recueillis à Alexandrie, ainsi que d'ouvrages antérieurs aujourd'hui perdus, notamment celui d'Hécatée d'Abdère ${ }^{142}$.

Après la mort d'Osiris, Isis, nous raconte Diodore, régna avec justice sur l’Égypte. Enlevée aux hommes, elle bénéficia d'honneurs divins. Son corps fut enterré à Memphis, où l'on montre encore, à l'époque de Diodore, le tombeau d'Isis dans le temple d'Héphaïstos, identifié au dieu égyptien Ptah. Toutefois, certains contestent cette tradition (édition de P. Bertrac et al., traduction personnelle inspirée de celle d'Y. Vernière ${ }^{143}$ ) :

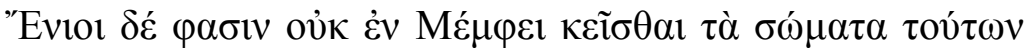

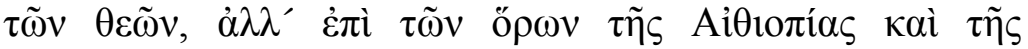

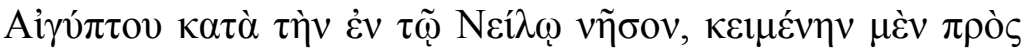

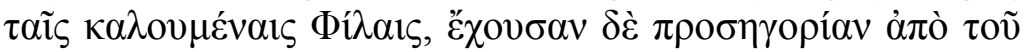

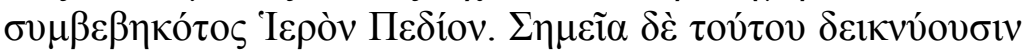

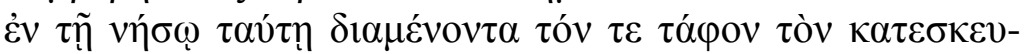

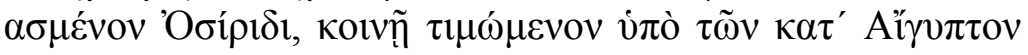

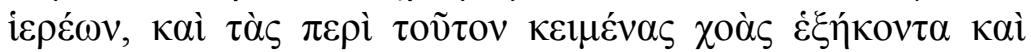

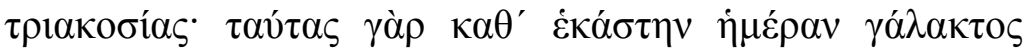

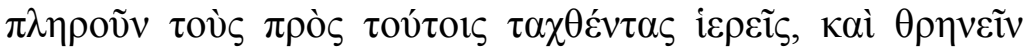

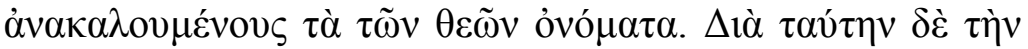

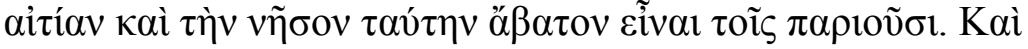

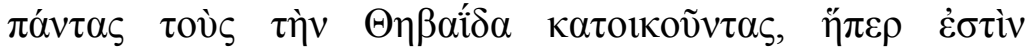

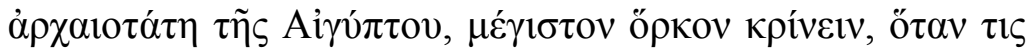

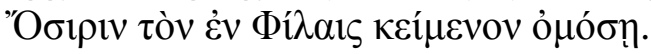

Cependant, certains disent que les corps de ces dieux (Osiris et Isis) ne reposent pas à Memphis, mais aux frontières de l'Éthiopie et de l'Égypte, au cœur d'une île sur le Nil, qui est située en face d'un lieu nommé Philae et qui a reçu pour

\footnotetext{
139 JUNKER, p. 79.

140 JUNKER, p. 40, fig. 9.

${ }^{141} \mathrm{~J}$. YOYOTTE, loc. cit., p. 102. Sur les répliques de la jambe d’Osiris en Haute-Égypte (à Thèbes, à Edfou, etc.), voir L. CoulON, loc. cit., p. 37.

${ }^{142}$ Historien des $\mathrm{IV}^{\mathrm{e}}$ et $\mathrm{III}^{\mathrm{e}}$ siècles avant notre ère, Hécatée d'Abdère est l'auteur d'Aegyptiaca, œuvre aujourd'hui perdue traitant d'histoire et de religion égyptiennes.

${ }^{143}$ Diodore de Sicile, Bibliothèque historique (CUF), texte établi par P. BERTRAC et al., traduit par Y. VERnièRE, Paris, 1993, p. 56-57.
} 
cela ${ }^{144}$ le nom de «Sol sacré ». Ils montrent, comme preuves de cette affirmation, des indices qui subsistent dans cette île, le tombeau érigé en l'honneur d'Osiris et vénéré en commun par les prêtres d'Égypte, ainsi que les 360 vases à libations qui se trouvent autour de lui. En effet, chaque jour, les prêtres chargés de cette fonction remplissent de lait ces (vases) et entonnent des chants funèbres en invoquant les dieux par leur nom. C'est pour cette raison que cette île est

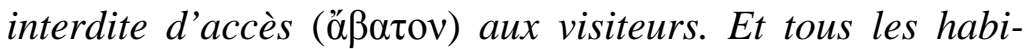
tants de la Thébaïde, qui est la région la plus ancienne d'Égypte, estiment comme le plus grand serment lorsqu'on jure par Osiris qui gît à Philae.

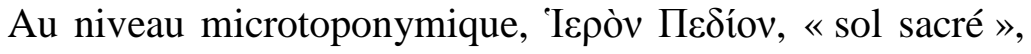
est une bonne traduction de l'égyptien ' $13 t w^{c} b t$, « butte pure ». Par ailleurs, Diodore évoque des «indices qui subsistent dans cette île », qui correspondent probablement au temple ptolémaïque de Biggeh. Les deux monuments importants de l'île sont mentionnés par le Décret I : il s'agit du temple et de la tombe d'Osiris qu'il renferme. Or, de façon similaire au Décret I, Diodore mentionne conjointement les $\delta 1 \alpha \mu \varepsilon ́ v o v \tau \alpha$, c'est-àdire les vestiges du complexe cultuel fonctionnel à l'époque de Diodore, et le tombeau érigé en l'honneur d'Osiris ( $\tau$ óv $\tau \varepsilon$

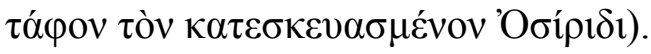

Comparons à présent le texte de Diodore à celui du Décret à propos des libations rituelles :

Diodore : Ils montrent, comme preuves de cette affirmation, des indices qui subsistent dans cette île, le tombeau érigé en l'honneur d'Osiris et vénéré en commun par les prêtres d'Égypte, ainsi que les 360 vases à libations qui se trouvent autour de lui.

Décret I : On dressera pour lui 365 tables d'offrande autour de ce territoire, tandis que des feuilles de palme seront disposées sur celles-ci. On ne permettra pas que les libations sur celles-ci ne viennent à manquer aucun jour, ni que l'eau ne vienne à manquer tout autour de ce territoire.

Au lieu des 365 tables d'offrande du Décret, Diodore parle de 360 vases à libation. Mais il rend correctement htpw par

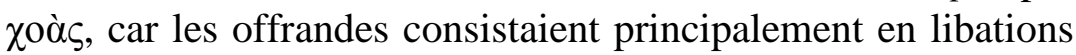

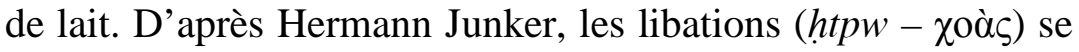
composaient uniquement de lait et non d'eau à Philae, en raison de l'influence des coutumes religieuses nubiennes ${ }^{145}$. Les prêtres entretenaient, à la place d'Isis et d'Horus-Khnoum ${ }^{146}$, la

\footnotetext{
${ }^{144}$ C’est-à-dire parce que cette île contient la dépouille d’Osiris.

145 JunKER, p. 76 ; J. W. YELLIN, «Abaton-Style Milk Libation at Meroe », dans Meroitic Studies 6 (1982), p. 151-155.

${ }^{146}$ Horus était étroitement associé à Khnoum à la première cataracte où le dieu de la fertilité était prédominant.
} 
vigueur d'Osiris à l'origine de la crue, en vivifiant les arbres de son bosquet au moyen de libations versées à partir des tables disposées le long des arbres.

En dépit de la légère erreur de dénombrement, il y a donc un accord presque complet entre le Décret et le témoignage de Diodore, qui montre que l'historien disposait de bonnes sources. En revanche, une différence subsiste entre les assertions de Diodore et le Décret : alors que ce dernier affirme que les tables à libation étaient dressées autour de ce territoire ( $m$ phr $m$ spt $t n)$, l'historien relate que les mêmes tables, évoquées par le biais des vases à libation, se trouvaient autour du tombeau

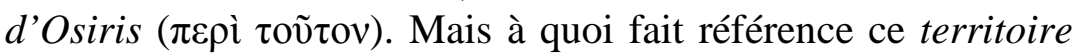
qui apparaît dans le Décret I ? Etant donné la nature escarpée et rocheuse de Biggeh, il semble que ce territoire ne désigne pas l'ensemble de l'île, mais la partie du temple censée contenir la tombe d'Osiris. En effet, le terme spt est parfois utilisé pour décrire une nécropole ${ }^{147}$. Les deux textes disposent dès lors les tables à libation autour du sépulcre.

Comparons à présent les deux textes en ce qui concerne les prêtres concernés et leurs fonctions :

Diodore : En effet, chaque jour, les prêtres chargés de cette fonction remplissent de lait ces (vases) et entonnent des chants funèbres en invoquant les dieux par leur nom.

Décret I : Le rituel divin sera accompli chaque jour par le grand-prêtre, qui effectue son office mensuel. Le choachyte d'Isis, dame de Philae, accomplira la libation sur celles-ci chaque jour.

Selon les deux sources, ce sont des prêtres dotés d'un statut particulier qui accomplissent les rites de libation et du culte divin: Diodore parle de prêtres chargés de plusieurs tâches auxquels correspondent deux prêtres distincts et spécialisés dans le Décret. Le texte égyptien est plus précis, puisqu’il attribue les deux fonctions décrites par Diodore respectivement à un grand-prêtre $\left(w^{c} b^{`}\right)$ et à un choachyte $(k b h w)$, membres de la classe supérieure des prêtres- $w^{`} b w$, les prêtres initiés ${ }^{148}$. En effet, les classes inférieures de prêtres (prêtres-lecteurs ou ritualistes) étaient sans doute exclues de l'accès à l'île sacrée ${ }^{149}$. Bien que Diodore ne fait qu'évoquer l'emplissage de vases avec du lait, il est clair qu'il fait référence aux libations rituelles. Le choachyte d'Isis devait utiliser une table à libation différente pour chaque jour de l'année. Ainsi, le Décret se révèle, de façon tout à fait cohérente, plus proche des réalités locales et il offre plus de nuances et de précisions.

\footnotetext{
${ }^{147}$ Wb. IV, p. 98-99.

${ }^{148}$ Voir G. ZAKI, Le Premier Nome de Haute-Égypte du III siècle avant J.-C. au VII siècle après J.-C., Turnhout, 2009, p. 181.

149 JUNKER, p. 76.
} 
D’après Diodore, plusieurs prêtres étaient là pour « entonner des chants funèbres en invoquant les dieux par leur nom »

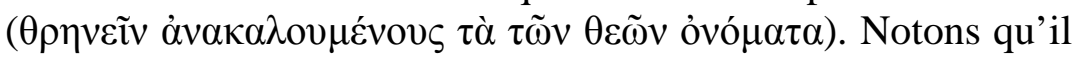
est le seul des auteurs classiques à mentionner des " chants funèbres ». Si Junker interprète ces chants comme des chants de lamentations sur la mort d'Osiris ${ }^{150}$, pour notre part, nous y verrions volontiers le « rituel divin accompli chaque jour par le grand-prêtre » mentionné par le Décret, c'est-à-dire le Rituel du culte divin journalier ${ }^{151}$, dont le contenu est intimement lié à la mort d'Osiris et à sa résurrection, et qui, de surcroît, regorge d'invocations et d'épithètes divines. À ce sujet, les lamentations occupaient une grande place dans la célébration des Mystères osiriens, comme en atteste le papyrus Dogson ${ }^{152}$. Toutefois, Diodore indique que ces chants funèbres étaient célébrés quotidiennement, comme dans le cas du Rituel du culte divin journalier, alors que les Mystères n'étaient organisés qu'une fois par an.

Nous constatons chez Diodore une reproduction consciencieuse des lignes directrices du Décret ${ }^{153}$, reproduites dans l'ordre exact du texte égyptien. Le nom et la situation de l'île sont fidèlement rendus, de même que son caractère sacré. Comme dans le Décret, Diodore évoque le tombeau d'Osiris, puis les libations, les rites journaliers et l'interdiction d'accès. Malgré une légère déformation au niveau du nombre de tables à libation, il est possible d'affirmer que Diodore disposait d'une source fiable et fidèle ${ }^{154}$, d'origine égyptienne.

\section{B. STRABON, Géographie, XVII, 44}

Strabon rapporte une interdiction de la musique semblable à celle pratiquée sur l'Abaton de Biggeh (édition de H. L. Jones ${ }^{155}$; traduction personnelle inspirée de celle de S. Emerit $\left.{ }^{156}\right)$ :

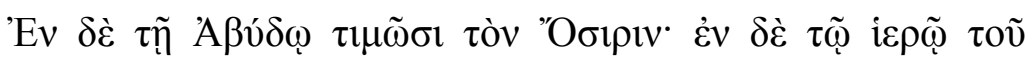

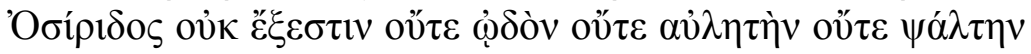

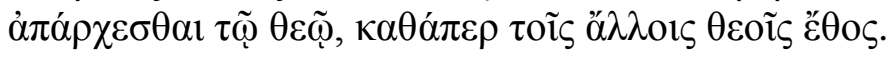

À Abydos on vénère Osiris ; et dans le temple d'Osiris il n'est permis ni à un chanteur, ni à un aulète, ni à un har-

\footnotetext{
150 JUNKER, p. 76.

${ }^{151}$ A. MORET, Le rituel du culte divin journalier en Égypte d'après les papyrus de Berlin et les textes du temple de Séti $I^{\text {er }}$ à Abydos (Annales du Musée Guimet. Bibliothèque d’études, 14), Paris, 1902.

152 JUNKER, p. 77.

${ }^{153}$ Ibidem.

${ }^{154}$ Ibidem.

155 The geography of Strabo. Volume VIII. Book 17 (The Loeb classical library 267), traduit par H. L. JoNES, London, 1966-1970.

156 S. EMERIT, «À propos de l'origine des interdits musicaux dans l’Égypte ancienne », dans BIFAO 102 (2002), p. 193.
} 
piste de préluder aux rites en l'honneur du dieu, comme il est d'usage de le faire pour les autres dieux.

Comparons l'interdiction de la musique décrite par Strabon au sujet du temple d'Abydos et celle rapportée par le Décret I au sujet de l'Abaton :

Strabon : (...) et dans le temple d'Osiris il n'est permis ni à un chanteur, ni à un aulète, ni à un harpiste de préluder aux rites en l'honneur du dieu, comme il est d'usage de le faire pour les autres dieux.

Décret I : On ne permettra pas de battre du tambourin et de jouer de la harpe ou du hautbois.

Le double hautbois ( $w \underline{d n y t}$, nommé ỏv $\lambda$ ós par Strabon) et la harpe sont prohibés dans les deux lieux sacrés ${ }^{157}$. Toutefois, Strabon se distingue par la mention d'une interdiction liée au chant et par la précision du moment concerné. Selon nous, Strabon fait peut-être allusion à l'absence particulière de chant et d'accompagnement musical aux prémices des cérémonies du rituel journalier célébré dans le temple d'Abydos en l'honneur d'Osiris. L'interdit abydénien se limiterait donc à un moment précis de silence observé quotidiennement.

De façon similaire à Biggeh, l'interdiction formelle de la musique et du bruit devait être limitée à certaines périodes, en l'occurrence aux Mystères d'Osiris et aux jours sacrés de la venue d'Isis à Biggeh ${ }^{158}$. En effet, dans le Décret, l'interdit musical est le seul à ne pas être suivi de $r^{c} n b$, « quotidiennement », ce qui indique son « caractère transitoire » ${ }^{159}$. La diversité des instruments concernés reflète un rejet global du bruit ${ }^{160}$ à Biggeh. Le Décret ne mentionne également pas le chant, qui était sans doute autorisé à Biggeh comme en atteste Diodore de Sicile (cf. supra). Il semble qu'une loi générale, dépassant le cadre de Biggeh, s'appliquait aux lieux contenant une relique de la dépouille d’Osiris et imposait un silence rituel lié au deuil $^{161}$ et au repos tranquille d'Osiris.

\section{SÉNÈQUE, Questions naturelles, IV A, 2, 7}

Voici le texte de Sénèque $(-1$ +65) (édition de P. Oltramare, traduction personnelle inspirée de celle de P. Oltramare $\left.{ }^{162}\right)$ :

\footnotetext{
${ }^{157}$ Les termes musicaux utilisés par Strabon dans cet extrait renvoient à des réalités égyptiennes au moyen de mots grecs interprétables suivant le contexte local. Voir S. EMERIT, loc. cit., p. 197.

${ }^{158}$ Voir Décret I, 1.7 ; 9. IDEM, p. 207.

${ }^{159}$ Ibidem.

${ }^{160}$ IDEM, p. 203.

161 IDEM, p. 197.

${ }^{162}$ Sénèque. Questions naturelles, vol. II, texte établi et traduit par P. OltRAMARE, Paris, 1929, p. 182.
} 
Primum incrementum Nili circa insulam quam modo rettuli Philas uisitur. Exiguo ab hac spatio petra diuiditur - Abaton Graeci uocant, nec illam ulli nisi antistites calcant ; illa primum saxa auctum fluminis sentiunt. Post magnum deinde spatium duo eminent scopuli - Nili uenas uocant incolae ex quibus magna uis funditur, non tamen quanta operire possit Aegyptum. In haec ora stipem sacerdotes et aurea dona praefecti, cum sollemne uenit sacrum, iaciunt.

C'est aux alentours de Philae, l'île dont je parlais à l'instant, que l'on voit le début de la crue du Nil. À une faible distance de celle-ci, il est divisé par un rocher - les Grecs l'appellent 'A $\beta \alpha \tau \mathrm{ov}$, et il n'est permis à personne sauf aux prêtres d'y mettre le pied ; ces pierres sont les premières à sentir la montée du fleuve. À une grande distance de là, s'élèvent deux écueils - les habitants les appellent les "Veines du Nil»-, desquels un fort courant d'eau se répand, mais pas au point de couvrir l'Égypte. Lorsque revient la fête sacrée annuelle, les prêtres jettent dans ces bouches du fleuve l'offrande rituelle et les présents en or du préfet.

Sénèque semble bien informé sur la situation géographique de Biggeh, qu'il situe à peu de distance de Philae en décrivant l'Abaton comme une île rocheuse. Sa dernière phrase renvoie à la légende selon laquelle le Nil prendrait sa source au niveau des écueils, des montagnes de Biggeh. Cette vision mythique a une grande portée théologique, puisque c'est à partir de l'île où repose Osiris, identifié au Nil, que renaît le fleuve lors de sa crue, tout comme le dieu se régénère dans sa tombe. Parmi les sources classiques concernant l'Abaton de Biggeh, Sénèque est le seul à parler d'offrande rituelle (stipem) jetée dans le Nil, action qui symboliserait un don direct à Osiris-Nil.

Les uenae Nili étaient deux pointes rocheuses situées sur les rives opposées du fleuve entre Syène et Éléphantine et d'où, pensait-on, émergeaient les sources du Nil. Il faut probablement les identifier aux $\delta$ ò ò $\rho \varepsilon \alpha$ dont parle Hérodote en II, 28, en les nommant K$\rho \tilde{\omega} \varphi \mathrm{r}$ et $\mathrm{M} \tilde{\omega} \varphi \imath^{163}$, mais aussi avec les duae petrae de Sénèque, Quaestiones naturales, 6, 8, $4^{164}$. Comme l'atteste la représentation des sources du Nil à Philae (fig. 7), les deux montagnes mentionnées par Hérodote et le gouffre peuvent être localisées à hauteur de Biggeh, sinon plus haut ${ }^{165}$. Comme le bras du Nil entre Biggeh et Philae est particulièrement encais-

\footnotetext{
${ }^{163}$ H. BEINLICH, « Die Nilquellen nach Herodot », dans ZÄS 106 (1979), p. 11-14, interprète ces toponymes comme deux phrases égyptiennes qu'Hérodote fut incapable de comprendre : krw p ’y, «C'est la berge » (désignant Syène), et $m^{3} t p^{3} y$, « C’est l'île » (désignant Éléphantine).

${ }^{164}$ Voir M. Annaei Lucani Bellum civile. Liber X, texte établi par E. BERTI, Florence, 2000, p. 243.

165 J. YoyotTe, «Études géographiques I. La « Cité des Acacias » (Kafr Ammar) », dans RdÉ 13 (1961), p. 104 ; JUNKER, p. 37 sq.
} 
sé ${ }^{166}$, les théologiens de Philae ont imaginé que l’inondation naissait de ces profondeurs.

En outre, le préfet romain d'Égypte devait sans doute se concilier le clergé puissant de l'Abaton de Biggeh. C'est pourquoi il lui offrait des présents en or (aurea dona) pour la fête sacrée annuelle (sollemne sacrum).

Malgré le manque d'informations précises sur la topographie de l'Abaton lui-même, l'extrait de Sénèque insiste sur le lien entre le retour de la crue du Nil et l'île rocheuse de Biggeh, la première terre égyptienne à " sentir la montée du fleuve » (illa primum saxa auctum fluminis sentiunt).

\section{LUCAIN, La guerre civile, $\mathrm{X}, 323-326$}

Lucain (39-65) montre César prononçant un discours admiratif sur le Nil auquel il s'adresse. À l'approche de Philae, le Nil, dit-il, rassemble ses ondes, puis franchit violemment les rapides qui forment la première cataracte. Au-delà s'élève une roche sacrée (édition et traduction personnelles inspirées de celles d'A. Bourgery et M. Ponchont ${ }^{167}$ ) :

323 Hinc, Abaton ${ }^{168}$ quam nostra uocat ueneranda uetustas, 324 terra potens ${ }^{169}$ primos sentit percussa tumultus

${ }^{166}$ A. BERnAND, Inscriptions grecques de Philae, II, Paris, 1969, p. 131, $\mathrm{n}^{\circ} 158$.

167 Lucain. La guerre civile (La Pharsale), texte établi et traduit par A. Bourgery et M. PonCHONT, Paris, 1926-1929, p. 197.

${ }^{168}$ La forme Abaton que présente cet extrait est l'accusatif féminin singulier de type grec du mot Abatos, -i (issu du mot grec äß $\beta \tau$ ov). Citant le vers 323 de Lucain, le passage de Servius sur l'Abaton atteste la forme Abatos, et non Abaton. Il semble que Servius ait mal compris la construction de Lucain en citant le seul vers 323 avec le relatif quam, alors qu'il ne cite pas le vers 324 qui contient son antécédent, terra potens, indispensable au sens et au respect de la syntaxe latine.

${ }^{169}$ L'édition d'A. Bourgery et M. Ponchont privilégie la conjecture du philologue humaniste français du $\mathrm{XVI}^{\mathrm{e}}$ siècle Claude Saumaise : petra patens, «large roche ». L'expression terra potens a certes suscité de nombreux doutes, mais la leçon attestée est défendue par A. Hudson-Williams (« Notes on Some Passages of Lucan », dans The American Journal of Philology 97.2 (1976), p. 134-137), qui, reprenant une idée avancée dans une note de l'édition de Bourgery-Ponchont, propose de comprendre potens dans un sens religieux par référence à l'importance de l'Abaton comme lieu de culte (potens (numine dei)). Un parallèle assez proche se trouve notamment dans la Thébaïde de Stace $(8,337)$. De plus, la leçon attestée par les manuscrits constitue une lectio difficilior et semble donner plus de sens au texte. Le terme potens signifierait alors "très sacré ", " sacro-saint ", avec un sens plus fort que celui du terme sacer. Les inscriptions grecques de Philae qualifient l'’A $\beta \alpha \tau$ ov de $\pi$ o $\lambda v ́ \sigma \varepsilon \mu \nu o v, ~ "$ très vénérable ", " très auguste», épithète également plus expressive que ípóv. Voir A. BERNAND, Inscriptions grecques de Philae, II, Paris, 1969, p. 131, nº 158 ; R. CAGNAT, J. TOUTAIN et G. LAFAYE, Inscriptiones graecae ad res romanas pertinentes, I, Chicago, 1975, p. 5, n 1313. 
325 et scopuli, placuit fluuii quos dicere uenas, 326 quod manifesta noui primum dant signa tumoris.

Au-delà, une terre douée de vertus surnaturelles, que notre vénérable tradition nomme Abatos, ressent la première le choc des flots tumultueux, de même que les écueils qu'il parut bon d'appeler les "Veines du fleuve », parce qu'ils fournissent les premiers signes visibles de la nouvelle crue.

Il est clair que Lucain s'est inspiré du passage de Sénèque sur l'Abaton. Les parallélismes lexicaux qui suivent suffisent à établir un rapprochement et une filiation entre les deux sources : scopuli ; Nili uenas (Sénèque) et fluuii uenas (Lucain); primum sentiunt (Sénèque) et primos sentit (Lucain). De plus, les vers 324 et 326 reprennent l'idée de Sénèque lorsqu'il dit que « ces pierres sont les premières à sentir la montée du fleuve " (illa primum saxa auctum fluminis sentiunt). Les similitudes avec le texte de Sénèque sont évidentes et le passage de Lucain montre une bonne compréhension de celui-ci ${ }^{170}$. Lucain pouvait avoir eu connaissance de l'importance religieuse de l'île - outre la mention de prêtres (antistites), d'une " offrande rituelle » (stipem) et d'une "fête sacrée annuelle » (solemne sacrum) dans l'extrait précédent de Sénèque ${ }^{171}$ - grâce à un traité sur les coutumes religieuses des Égyptiens écrit par ce dernier mais aujourd'hui perdu, qui fournissait sans doute des informations plus détaillées. Lucain a également pu tirer de plus amples informations du passage de Diodore de Sicile examiné plus haut. Un argument en faveur de cette hypothèse est la proximité sémantique entre les expressions terra potens (Lu-

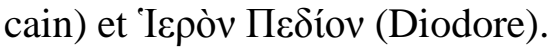

Parmi les sources classiques, seuls les extraits de Sénèque et de Lucain font état de la proximité des sources du Nil et de l'Abaton. Passant sous silence le motif véritable justifiant la sacralité du lieu (la présence de la tombe d'Osiris), les deux écrivains latins semblent croire que le caractère sacré du lieu est précisément dû à la proximité des sources du Nil. C'est pourquoi Lucain évoque avec emphase la haute sacralité de l'Abaton, de même que le caractère surnaturel attribué à l'île. Dès lors, ils omettent tous deux d'évoquer les interdits liés à la présence de la sépulture divine.

\section{E. Plutarque, Euvres morales, Sur Isis et Osiris, 20}

D’après Plutarque (vers 46-126), certains Égyptiens croient que le cadavre d'Osiris fut enseveli à Abydos, d'autres pensent

\footnotetext{
${ }^{170}$ E. Berti estime à l'inverse que ce passage de Lucain est assez confus et donne l'impression d'une lecture hâtive de la source. Voir M. Annaei Lucani Bellum civile. Liber X, texte établi par E. BERTI, Florence, 2000, p. 243.

171 Notons que Lucain omet ces éléments textuels dans son œuvre, puisqu'il ne fait qu'évoquer l'Abaton.
} 
qu'il le fut à Memphis, mais d'autres situent sa tombe sur une petite île inaccessible près de Philae (édition de Ch. Froidefond, traduction personnelle inspirée de celles de Ch. Froidefond et d'H. Junker ${ }^{172}$ ) :

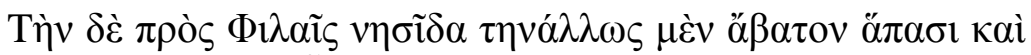

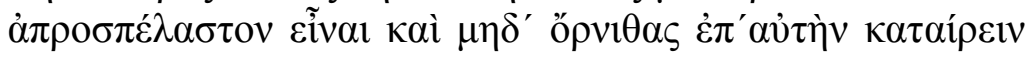

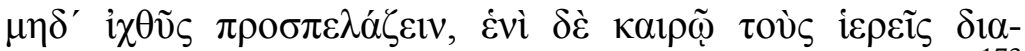

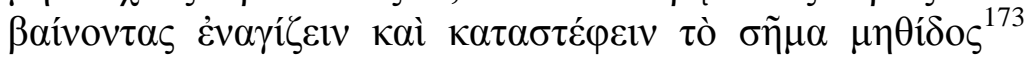


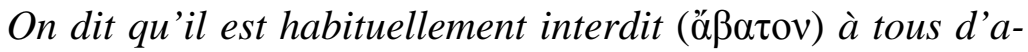
border et d'approcher la petite île située près de Philae, et que les oiseaux ne s'y posent pas et que les poissons ne s'en approchent pas. Mais, à un moment déterminé, les prêtres, faisant la traversée, $y$ offrent un sacrifice funéraire ${ }^{174}$ et ornent de couronnes le tombeau couvert d'ombre par un arbre « mêthis » qui surpasse en hauteur n'importe quel olivier.

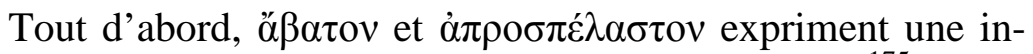
terdiction et non une impossibilité d'accéder à l'île ${ }^{175}$. Cette information correspond bien à ce que dit le Décret. L'interdiction ne tolère qu'une exception : lorsque les prêtres pénètrent dans le territoire sacré pour accomplir les rites devant le dieu. Plutarque affirme que cela ne se produit qu' "à un mo-

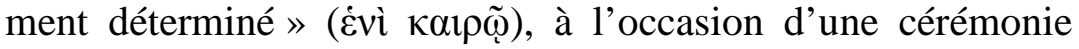
funéraire. En effet, la traversée annuelle visait à célébrer les Mystères d'Osiris, qui étaient l'événement principal du sanctuaire de Biggeh, et se déroulaient à la fin du mois de

\footnotetext{
${ }^{172}$ Plutarque. Euvres morales, tome 5, 2e partie, Isis et Osiris, texte établi et traduit par Ch. FroIDEFOND, Paris, 1988, p. 195 ; JUNKER, p. 69.

${ }^{173}$ La leçon la plus vraisemblable, attestée dans le manuscrit Laur. Plut. 80,21 , est $\mu \eta \theta i ́ \delta \eta \varsigma$. Toutefois, à la différence d'H. Junker, compte tenu des nombreuses aberrations présentes dans les manuscrits pour ce passage qui a pu paraître obscur à maints copistes, nous avons préféré suivre la conjecture de Wilhelm Schubart ( $\mu \eta \theta i \delta$ os), permettant de postuler la forme grecque $\mu \eta \theta i ́ s$ (génitif $\mu \eta \theta i ́ \delta o \varsigma$ ) décalquée sur le terme égyptien $m n t 3$. Dans $\mu \eta \theta i ́ \delta o \varsigma$

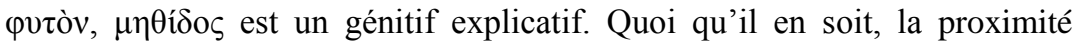
entre les deux termes ne peut être une coïncidence. Voir Plutarque. Euvres morales, tome 5, 2e partie, Isis et Osiris, texte établi et traduit par Ch. FROIDEFOND, Paris, 1988, p. 273-274, note 7. Si, comme le dit H. Junker, le nom $\mu \eta \theta i \delta \emptyset$ fait figure de crux interpretum, il ne nous semble pas pour autant demeurer un locus desesperatus. La chute du $n$ devant un $t$ s'observe souvent en copte, où le relatif du moyen-égyptien nty devient et . D'après lui, la forme $m n t$ ' devait se prononcer « mēetâ » suivant une évolution tardive de l'égyptien dont on trouve des traces dans les dialectes coptes. Voir JuNKER, p. 73.

${ }^{174}$ Il est intéressant de noter que Plutarque utilise ici le verbe $\dot{\varepsilon} v \alpha \gamma i \zeta \omega$, « offrir un sacrifice à un demi-dieu ou un mort», et non $\theta v ́ \omega$, «offrir un sacrifice à un dieu ». Il marque ainsi de manière lexicale le caractère à la fois divin et périssable qui caractérise Osiris dans la religion égyptienne. Voir V. MAGNIEN et M. LACROIX, Dictionnaire grec-français, 1969, p. 570 et 836.

${ }^{175}$ JUNKER, p. 71.
} 
Khoiak $^{176}$. Les dieux faisaient alors eux aussi la traversée jusqu'à Biggeh. Les prêtres enterraient de nouveaux simulacres du corps d'Osiris dans le tertre de l'Abaton. Les cérémonies mettaient en scène l'enterrement et la résurrection d'Osiris. En revanche, Plutarque paraît ignorer l'institution d'un culte journalier.

Confrontons à présent les textes de Plutarque et du Décret en ce qui concerne la faune de l'île :

Plutarque : On dit (...) que les oiseaux ne s'y posent pas et que les poissons ne s'en approchent pas.

Décret I : Et on ne permettra de capturer aucun oiseau ni aucun poisson (sur une distance de) $[\mathrm{x}+] 40$ (coudées) vers le Sud, le Nord, l'Ouest et l'Est.

L'information étonnante de Plutarque, selon laquelle les oiseaux et les poissons éviteraient l'île et n'oseraient pas s'en approcher, trouve une explication correcte dans le Décret : la chasse et la pêche étaient prohibées autour de l'île. Il s’agirait donc ici d'une simple erreur de compréhension.

La procession que décrit Plutarque faisait partie des Mys-

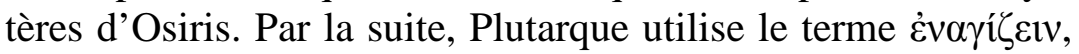
" offrir un sacrifice funéraire », qui peut tout à fait désigner une libation offerte au dieu défunt. Il ajoute que le tombeau d'Osiris

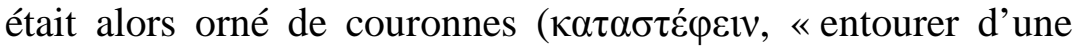
couronne »), alors que, dans le Décret, c'est sur les tables à libation entourant la tombe que sont disposées des feuilles de palme. La mention de l'olivier comme arbre de référence trahit l'influence de la pensée grecque sur la compréhension des sources par Plutarque ou par des commentateurs antérieurs. Toutefois, l'offrande d'une couronne au défunt est bien attestée à travers le rite ptolémaïque de la couronne ou guirlande de justification $^{177}$, qui avait pour but de légitimer l'accès de l'âme dans l'Au-delà.

L'arbre $\mu \eta \theta$ ís, qui ombrageait la tombe d'Osiris d'après Plutarque, paraît transcrire en grec le nom du bosquet $m n t^{3}$ mentionné dans le Décret à la fin de la colonne 5. Plutarque insiste sur la hauteur et la robustesse de l'arbre, ce qui corrobore l'hypothèse de la présence d'un grand arbre majestueux, comme le sycomore élevé sur le tertre, et infirme l'idée d'un arbrisseau.

Cependant, chez Plutarque, il est question d'un seul arbre, et non d'un bosquet tout entier. Dans la légende d'une représentation d'Osiris à droite du Décret, le dieu est désigné comme

\footnotetext{
${ }^{176}$ É. CHASSINAT, Le mystère d'Osiris au mois de Khoïak, Le Caire, 1966, p. 91.

177 Voir P. DERChAIN, « La couronne de justification. Essai d'analyse d'un rite ptolémaïque », dans Chronique d'Égypte 30 (1965), p. 225-287 ; S. KAMEL, « La couronne ou la guirlande de la justification offerte au défunt ou au dieu pour le justifier », dans Arab Archaeologists (2008), p. 1-35.
} 


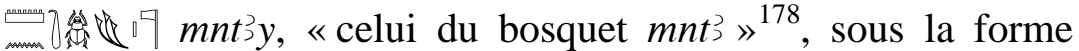
d'un adjectif nisbé. L'arbre iwy vénérable, puisqu'il constitue une hypostase d'Osiris, a pu également être désigné comme «celui qui est lié au bosquet» $(m n t 3 y)^{179}$, épiclèse d'Osiris attestée à Philae. Cette hypothèse expliquerait la confusion présente chez Plutarque entre le bosquet et l'arbre sacrés. Toutefois, Plutarque est probablement tributaire de sources inexactes. Nous avons pu observer l'intérêt du témoignage de Plutarque à travers la présence d'éléments explicables en contexte égyptien tardif.

Diverses étymologies du bosquet $m n t 3$ ont été avancées. Junker avait pensé à un lien étymologique avec $m n w$, «plantation d'arbres », qui n'explique toutefois pas la présence de la dentale. Il retenait donc essentiellement une paronomase avec $m n t$, la « cuisse », en lien avec la nature de la relique locale ${ }^{180}$. Koemoth a formulé depuis lors une hypothèse séduisante qui illustrerait une des fonctions du bosquet: $m n t^{3}$ ? viendrait de $m n(w) t$, « qui fixe la terre ${ }^{181}$. En effet, les racines des arbres du bosquet permettaient d'empêcher l'érosion des rives en période de crue. Somme toute, le nom est très probablement issu d'un calembour, technique linguistique très appréciée des Égyptiens, mais il est possible, outre ce jeu de sonorités, que la signification première du mot soit liée à la topographie de l'Abaton.

\section{F. Claudien, Éloge de Stilichon, II, 424-436}

Claudien (vers 370-404) prononça son Panégyrique pour le consulat de Stilichon en 400, afin de célébrer le consulat de Stilichon, chef vandale nommé régent de l'empire romain pendant la minorité des fils de Théodose (titre latin de l'œuvre : De Consulatu Stilichonis).

Derchain a reconnu à juste titre une description mythique de l'Abaton de Biggeh dans un passage de l'Éloge de Stilichon. L'exposé qui suit s'appuie en grande partie sur son excellent $\operatorname{article}^{182}$, tout en étayant son propos. Cette source présente un grand intérêt, car elle nous éclaire sur la topographie mythique de l'Abaton représentée à Philae (fig. 7). De plus, ces vers de Claudien confirment que l'écrivain était originaire d'Alexandrie et nous permettent de croire qu'il a visité le temple de Philae. Voici ce texte, suivi d'une traduction à nouveaux frais qui respecte son caractère poétique et emphatique

\footnotetext{
${ }^{178}$ Voir Wb. II, p. 91 (13-14) ; JUNKER, p. 54.

179 JUNKER, p. 73.

${ }^{180}$ Voir JUNKER, p. 41.

${ }^{181} \mathrm{P}$. KOEMOTH, Osiris et les arbres : contribution à l'étude des arbres sacrés de l'Égypte ancienne (AegLeod 3), Liège, 1994, p. 121.

182 P. DERCHAIN, « À propos de Claudien. Éloge de Stilichon, II, 424436 », dans ZÄS 81 (1956), p. 4-6.
} 
(édition de Monumenta Germaniae Historica, Auctorum Antiquissimorum Tomus X, Claudii Claudiani Carmina, Berlin, 1892, p. 218) :

Est ignota procul nostraeque imperuia menti,

425 Vix adeunda deis, annorum squalida mater, Inmensi spelunca aeui, qua tempora uasto Suppeditat reuocatque sinu. Complectitur antrum, Omnia qui placido consumit numine, serpens Perpetuumque uiret squamis caudamque reductam

430 Ore uorat tacito relegens exordia lapsu.

Vestibuli custos uultu longaeua decoro

Ante fores Natura sedet, cunctisque uolantes

Dependent membris animae. Mansura uerendus

Scribit iura senex, numeros qui diuidit astris

435 Et cursus stabilesque moras, quibus omnia uiuunt Ac pereunt fixis cum legibus ${ }^{183}$.

Il y a, ignorée et lointaine, impénétrable à l'esprit humain, 425 Presque inaccessible aux dieux, mère ténébreuse des âges, Une caverne de l'immense éternité, au sein vaste de laquelle Elle produit et rappelle les temps. Un serpent enveloppe l'antre, Qui ronge toute chose de sa placide puissance, Et est perpétuellement florissant grâce à ses écailles,

430 Qui dévore sa queue repliée vers sa bouche

Revenant à ses origines d'un glissement silencieux.

Gardienne de l'entrée, une vieille au beau visage,

La Nature, se tient devant la porte, tandis que des âmes ailées

Sont suspendues à tous ses membres. Un vieillard vénérable

435 Inscrit des lois durables, lui qui divise les nombres au moyen des astres,

Ainsi que leur cours et les délais immuables, grâce auxquels tout vit Et périt selon des lois fixes.

Les vers 424-425, qui expriment le caractère reculé de l'île et la difficulté d'y accéder (procul nostraeque imperuia menti, Vix adeunda deis), renvoient à l'extrait de Servius que nous examinerons plus loin. Au vers 425, Claudien affirme que l'île est " presque inaccessible aux dieux ", puisque les dieux étaient autorisés à se rendre sur l'Abaton uniquement lors des cérémonies en l'honneur du Ba d'Osiris ${ }^{184}$.

La « caverne de l'immense éternité », dont parle Claudien, fait référence à la représentation de la caverne du Nil à Philae sur la face interne du mur nord de la Porte d’Hadrien (fig. 12).

183 Comme Derchain ne faisait référence à aucune édition, nous avons repris la seule édition critique du texte, ce qui entraîne la présence de différences remarquables dans le texte latin lui-même entre la version reproduite ici et celle publiée par Derchain.

${ }^{184}$ P. DERCHAIN, loc. cit., p. 5. 


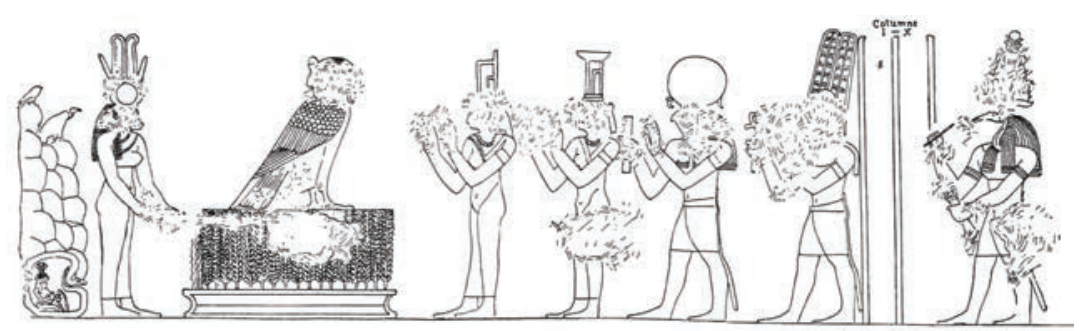

Fig. 12. Reliefs du mur nord de la Porte d'Hadrien (JunKER, p. 58)

La caverne est désignée comme celle « de l'immense éternité », parce qu'elle est englobée par un ouroboros, symbole ici de l'éternel retour de la crue et du rajeunissement perpétuel du Ba d'Osiris. En effet, la seule forme circulaire du corps du serpent évoque les notions de perfection et d'éternité. L'ouroboros représente la «non-existence régénérante qui encercle le monde ${ }^{185}$. Aussi l'Inondation est-elle conçue comme une résurgence du Noun ${ }^{186}$, le flot originel. Les Égyptiens donnent au non-existant la forme visuelle du "serpent recroquevillé » $(m h n)^{187}$, replié sur lui-même, tel qu'il est visible dans le relief. Bien que le serpent ne se morde pas la queue, on peut donc passer outre ce détail, puisque c'est la forme égyptienne de l'ouroboros. En outre, Claudien fait de cette caverne la «mère ténébreuse des âges » par référence à la périodicité annuelle de la crue du Nil.

Au vers 429, uiret traduit littéralement l'égyptien $w 3$, , « être vert, florissant, vigoureux, jeune ${ }^{188}$, lequel est attesté pour décrire Osiris, nommé "Celui du bosquet $m n t^{3}$ ”, ainsi que l'arbre iwy dans les inscriptions de Philae ${ }^{189}$. L'expression de Claudien "perpétuellement florissant grâce à ses écailles » (Perpetuumque uiret squamis) fait penser à la mue des serpents, image du rajeunissement du Ba d'Osiris, et à l'hydronyme $W_{3} \underline{d}$-wr, le « Très-vert », qui peut désigner le Nil. Le vers 430 nous montre que Claudien interprétait clairement le serpent comme un ouroboros, lui « qui dévore sa queue repliée vers sa bouche ». L'expression relegens exordia, littéralement " repassant par ses débuts ", siérait de même parfaitement au Nil, qui est " celui qui renouvelle sa jeunesse » (whm rnp) et « celui qui rajeunit son corps au début de l'année " $\left(r n p(w) h^{\complement} w\right.$.f tpy rnpt) dans les inscriptions de Philae ${ }^{190}$. Bien qu'il ne cite pas le Nil accroupi dans la grotte, le génie Hâpy, Claudien y fait nettement allusion ${ }^{191}$. Peut-être a-t-il choisi de centrer son poème

\footnotetext{
${ }^{185}$ Voir E. Hornung, Les dieux de l'Égypte. Le Un et le Multiple, Paris, 1986, p. 149 ; 162-163. Pour les Égyptiens, le non-existant ne s’arrête pas aux limites de la création ; il imprègne toute la création en la régénérant.

186 Voir P. KоEMOTH, Osiris et les arbres : contribution à l'étude des arbres sacrés de l'Égypte ancienne, Liège, 1994, p. 3.

${ }^{187}$ Voir E. HORNUNG, op. cit., p., p. 162.

${ }^{188}$ P. DERCHAIN, loc. cit., p. 5.

189 JUNKER, p. 53-54.

${ }^{190}$ P. DERCHAIN, loc. cit., p. 5 ; JUNKER, p. 39.

${ }^{191}$ P. DERCHAIN, loc. cit., p. 5.
} 
sur le serpent davantage que sur le Nil, parce que l'ouroboros était un support plus adapté et intelligible pour les lecteurs latins ${ }^{192}$, ou simplement en raison de la signification plus riche et de l'importance particulière de ce symbole aux yeux des Égyptiens à l'époque hellénistique et romaine.

Dans les vers 431-432, Claudien décrit très fidèlement la déesse Hathor-Isis, postée comme " gardienne de l'entrée ", qui "se tient devant la porte ». Il la qualifie de "vieille au beau visage », utilisant là encore une expression égyptienne, en l'occurrence une épithète d'Hathor-Isis, " celle qui a beau visage » $(h r n f r)^{193}$. Hathor-Isis est identifiée avec la Nature, comme le mentionnent Plutarque et Athénagore d'Athènes ${ }^{194}$. Comme l'indique Derchain, « Devant Isis-Hathor, au-dessus du buisson sacré se tient l'âme d'Osiris sous forme d'un oiseau à tête humaine, qui est exactement une âme ailée ${ }^{195}$ (v. 432-433 : uolantes ... animae).

Les vers 433-436 décrivent le dieu Thot, figuré bien plus à droite, après le bosquet sacré, quatre divinités et le texte du Décret. Du reste, Claudien ne parle d'aucun de ces éléments situés entre le bosquet sacré surmonté du Ba d’Osiris et Thot. Le poète alexandrin dit qu' « un vieillard vénérable inscrit des lois durables ». Or, selon Derchain, « Thot est souvent représenté comme un dieu très ancien » et "mansura ... scribit iura rappelle les épithètes de Thot» le dépeignant comme l'ordonnateur de l'univers, par exemple «celui qui établit les lois » $(\operatorname{smn}(w) h p w)^{196}$. De plus, Thot se caractérise par sa fonction de scribe divin, qu'il exerce justement sur le bas-relief dont Claudien parle dans ces vers ${ }^{197}$ et dans la rédaction du Décret gravé à gauche de ce bas-relief. Le dieu-scribe, en tant que dieu lunaire, «divise les nombres (de mois et d'années) au moyen des astres $"{ }^{198}$. Par ailleurs, de nombreuses épithètes de Thot insistent sur le rôle décisif qui est le sien ${ }^{199}$ lorsqu'il écrit le destin du monde selon les décisions de Rê.

Nous avons tenté d'approfondir l'interprétation de Derchain en mettant en avant la concordance théologique et symbolique entre le témoignage de Claudien et les reliefs égyptiens à caractère religieux, en plus des rapprochements textuels et iconographiques. Nous concluons cette partie en observant que les

192 Ibidem.

${ }^{193}$ Ibidem.

${ }^{194}$ Ibidem ; T. HOPFNER et C. CLEMEN, Fontes historiae religionis Aegyptiacae (Fontes historiae religionum ex auctoribus graecis et latinis collectos, 2), Bonn, 1922-1925, p. 344. Voir PluTARQUE, Sur Isis et Osiris, 38.

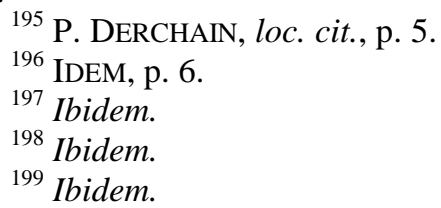


quatre personnages actifs de la scène de Philae sont repris par Claudien dans l'ordre exact de gauche à droite ${ }^{200}$ : la caverne entourée du serpent, Hathor-Isis, le Ba d'Osiris et Thot dans sa fonction de scribe.

\section{G. SERVIUS, Commentaire sur l'Énéide de Virgile, VI, 154}

L'édition et la traduction du texte se fondent sur celles d'Emmanuelle JEUNET-MANCY ${ }^{201}$ :

LUCOS STYGIS ET REGNA INVIA VIVIS ASPICIES : Seneca scripsit de situ et de sacris Aegyptiorum. Hic dicit circa Syenen, extremam Aegypti partem, esse locum quem Philas, hoc est amicas, uocant ideo quod illic est placata ab Aegyptiis Isis, quibus irascebatur quod membra mariti Osiridis non inueniebat, quem frater Typhon occiderat. Quae inuenta postea cum sepelire uellet, elegit uicinae paludis tutissimum locum, quam transitu constat esse difficilem ; limosa enim est et papyris referta et alta. Vltra hanc est breuis insula, inaccessa hominibus, unde Abatos appellata est ; Lucanus : hinc Abatos, quam nostra uocat ueneranda uetustas.

LUCOS STYGIS ET REGNA INVIA VIVIS ASPICIES : Sénèque a écrit sur le pays et sur les pratiques religieuses des Égyptiens. Dans ces écrits, il dit qu'aux alentours de Syène, aux confins de l'Égypte, il existe un endroit qu'on appelle Philae, c'est-à-dire "les amies », parce que c'est là qu'Isis fut apaisée par les Égyptiens, contre lesquels elle était en colère de ne pas retrouver les membres de son mari Osiris, que son frère, Typhon, avait tué. Une fois qu'elle les eut retrouvés, voulant les ensevelir, elle choisit l'endroit le plus sûr du marais voisin, qui est - c'est un fait établi - difficile à traverser, car il est vaseux et rempli de papyrus, et profond. Au-delà de ce marais, il y a une petite île, inaccessible aux hommes et, pour cette raison, appelée Abatos; Lucain : "puis c'est Abatos, que par une vénérable tradition nous nommons ainsi ».

Servius (début du $5^{\mathrm{e}}$ siècle de notre ère) se fonde vraisemblablement sur le témoignage de Lucain et sur des sources aujourd'hui perdues. Le commentateur de l'Énéide devait disposer d'une source portant sur un marais voisin de l'Abaton, vu qu'il est le seul parmi tous les auteurs classiques à en mentionner l'existence.

Servius rapporte qu'Isis se mit en colère parce qu'elle ne retrouvait pas le corps de son époux. Or, ce récit ne correspond ni au mythe d'Osiris, ni à l'image traditionnelle d'Isis se lamen-

\footnotetext{
${ }^{200}$ Ibidem.

${ }^{201}$ Servius. Commentaire sur l'Énéide de Virgile, livre VI, texte établi, traduit et commenté par E. JEUNET-MANCY Paris, 2012, p. 58. Voir aussi la traduction de JUNKER, p. 78.
} 
tant et pleurant la perte de la dépouille de son mari. En réalité, il semble que deux légendes, la recherche du corps d'Osiris et le mythe de la déesse lointaine (Hathor-Sekhmet/Tefnout) ${ }^{202}$, se soient mêlées pour donner cette version. Le récit de Servius se fonde donc sur une véritable tradition égyptienne, qui porte sur une déesse de Philae irritée puis apaisée. L’erreur de Servius se limite à l’identification de la divinité furieuse.

Un relief de Philae (Fig. 10) montre que c'est à travers un fourré de papyrus qu'Horus mène le corps de son père vers l'Abaton. Or, Servius parle d'un « marais voisin » de l'Abaton, "rempli de papyrus », ce qui renvoie peut-être à l'irrigation et la fertilité de la crique orientale de l'Abaton où se dressaient le temple et la tombe d'Osiris. Le signe du canal $\square$ (N36) présent dans les représentations du bosquet sacré nous invite également à cette interprétation.

Les tombeaux d'Osiris étaient habituellement installés sur une île ou sur une bande de terre presque complètement entourée par les eaux d'un lac ou d'un canal $i s ̌ r w^{203}$. La liste de Dendera cite, comme butte divine pour le premier nome, la Butte pure, et le nom de l'étendue d'eau où les prêtres allaient puiser pour former les figurines osiriennes dans le premier nome et

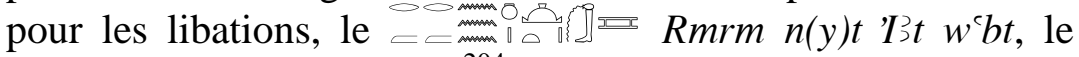
Remrem de la Butte pure ${ }^{204}$. Nous proposons de rapprocher l'hydronyme du verbe égyptien rmrm qui veut dire " châtier, punir » en lien avec l'interdiction formelle d'accès à l'Abaton. Junker affirme que la Douat supérieure de la butte divine de Busiris est, comme à Biggeh, séparée du temple par une étendue d'eau et forme une île (qu'il situe dans un lac sacré artificiel dans le cas de Busiris) ${ }^{205}$. De même, dans l'Osiréion d'Abydos, une île était entourée par un canal, ainsi qu'à OuPeqer, la butte osirienne d'Abydos. Il nous semble que la présence d'une étendue d'eau près d'un Abaton devait être perçue comme nécessaire pour les libations, la séparation entre espace sacré et profane et en raison de la symbolique de la butte primordiale. Toutefois, il est difficile de deviner aujourd'hui la configuration ancienne d'éléments apparemment répandus au

\footnotetext{
${ }^{202}$ Ce dernier mythe rapporte l'apaisement de la déesse Hathor-Tefnout, qui était partie en Nubie sous l'effet de la colère, et son retour en Égypte. Hathor-Tefnout est liée à l'Abaton, ainsi que sa transformation de déesse agressive en déesse apaisée : les inscriptions de Philae relatent que Sekhmet, la forme agressive d'Hathor-Tefnout, s'est rendue sur l'Abaton et a purifié son corps sur l'île, c'est pourquoi on la nomme «l'île pure » (iw w` $b$ ). Voir JUNKER, p. 78-79. Par conséquent, l’Abaton tire peut-être son nom égyptien de l'apaisement de la déesse, bien que cette explication ne repose sur aucun bien-fondé.

${ }^{203} \mathrm{P}$. Коемотн, Osiris et les arbres : contribution à l'étude des arbres sacrés de l'Égypte ancienne (AegLeod 3), Liège, 1994, p. 86.

204 JUNKER, p. 75.

205 JUNKER, p. 71.
} 
niveau archéologique mais peu attestés dans les sources textuelles. Nous pouvons tout de même certifier l'existence d'une étendue d'eau fort proche de l'Abaton sans plus de précisions sur sa localisation.

\section{$H$. Synthèse sur les sources classiques}

L'interdiction de fouler le sol de l'Abaton est bien attestée chez les auteurs antiques, puisqu'elle constitue la qualité la plus importante de l'île, son essence même : elle est ő $\beta \alpha \tau o v$, soit « interdite d'accès». Cela a pour conséquence de limiter les indices textuels sur la topographie réelle de l'Abaton. L'assimilation à l'Abaton grec est due à la délimitation cultuelle des tombes d'Osiris par rapport au monde profane et aux interdits liés au bruit. Bien qu'il n’y ait plus aucune preuve archéologique, la Porte d'Hadrien à Philae et les sources classiques nous livrent des témoignages concordants et probants ${ }^{206}$.

Junker ${ }^{207}$ constatait que les mêmes interdits étaient de règle dans toutes les zones où un mausolée d'Osiris, entouré de 365 tables d'offrande, se cachait dans un bois sacré, notamment à Abydos $^{208}$ et au sanctuaire osirien qui se trouvait « en avant des portes de Memphis $»{ }^{209}$. Sauneron a découvert que des interdictions comparables étaient liées au tombeau des «dieux morts » d'Esna ${ }^{210}$. La disposition et les rites différaient légèrement à Acanthôn ${ }^{211}$. Les sources classiques et égyptiennes indiquent que 365 tables d'offrande devaient se trouver autour du bosquet sacré, comme à Ou-Peqer, la butte divine d'Abydos ${ }^{212}$. La liste de Dendera montre que les rites accomplis sur l'Abaton ne font qu'imiter ceux du grand sanctuaire abydénien et devaient donc être de grande ampleur. Par ailleurs, la pratique de la butte artificielle sacrée est bien attestée au niveau archéologique, notamment à l'Osiréion de Karnak ${ }^{213}$ et à Oxyrhynchos ${ }^{214}$.

Il est clair que la partie sacrée, l'Abaton, ne s'étendait pas à toute l'île de Biggeh ${ }^{215}$. À l'origine, l'Abaton était vraisembla-

\footnotetext{
${ }^{206}$ E. WINTER, « Abaton », dans LÄ I, Wiesbaden, 1975, col. 1-2.

207 JUNKER, p. 69 sq.

${ }^{208}$ IDEM, p. 50, 78, 85.

${ }^{209}$ IDEM, p. 69-74.

210 S. SAUNERON, « L'Abaton de la campagne d'Esna », dans MDAIK 16 (1958), Le Caire, p. 271-279.

${ }^{211}$ J. YoYOTTE, «Études géographiques I. La « Cité des Acacias » (Kafr Ammar) », dans RdÉ 13 (1961), p. 103.

212 JUNKER, p. 70.

${ }^{213}$ L. Coulon, Fr. Leclère et S. Marchand, « Catacombes osiriennes de Ptolémée IV à Karnak. Rapport préliminaire de la campagne de fouilles 1993 », dans Cahiers de Karnak 10 (1995), p. 213-214.

214 H.I. AMER, «Les catacombes osiriennes d’Oxyrhynchos », dans L. Coulon (éd.), Le culte d'Osiris au I ${ }^{e r}$ millénaire av. J.-C. Découvertes et travaux récents, Paris, 2010, p. 269-282.

${ }^{215}$ Voir l'extrait de Diodore supra. JUNKER, p. 45.
} 
blement une butte osirienne liée au temple de Biggeh ${ }^{216}$. Pour Junker, comme l'inondation était censée jaillir du sud de Biggeh, l'Abaton devait se trouver près du temple au milieu de la pente de la partie sud de l'île ${ }^{217}$. En effet, l'appellation " Haute montagne » attestée à Philae montre clairement que la zone plane entre les pics nord et sud de Biggeh ne convient pas avec la notion de butte sacrée. Or, il n'y a pas assez d'espace à l'extrémité sud de l'île pour les installations de l'Abaton ${ }^{218}$. Ainsi, d'après Junker ${ }^{219}$, la tombe et le bosquet devaient se situer à l'extrême sud de l'échancrure de la côte orientale, là où se dressent aujourd'hui les habitations les plus au sud du village moderne de Biggeh (voir fig. 13). Les coordonnées géographiques plausibles de l'Abaton de Biggeh sont les suivantes: 2401’13.0"N 3253’08.7"E (24.020283, 32.885758).

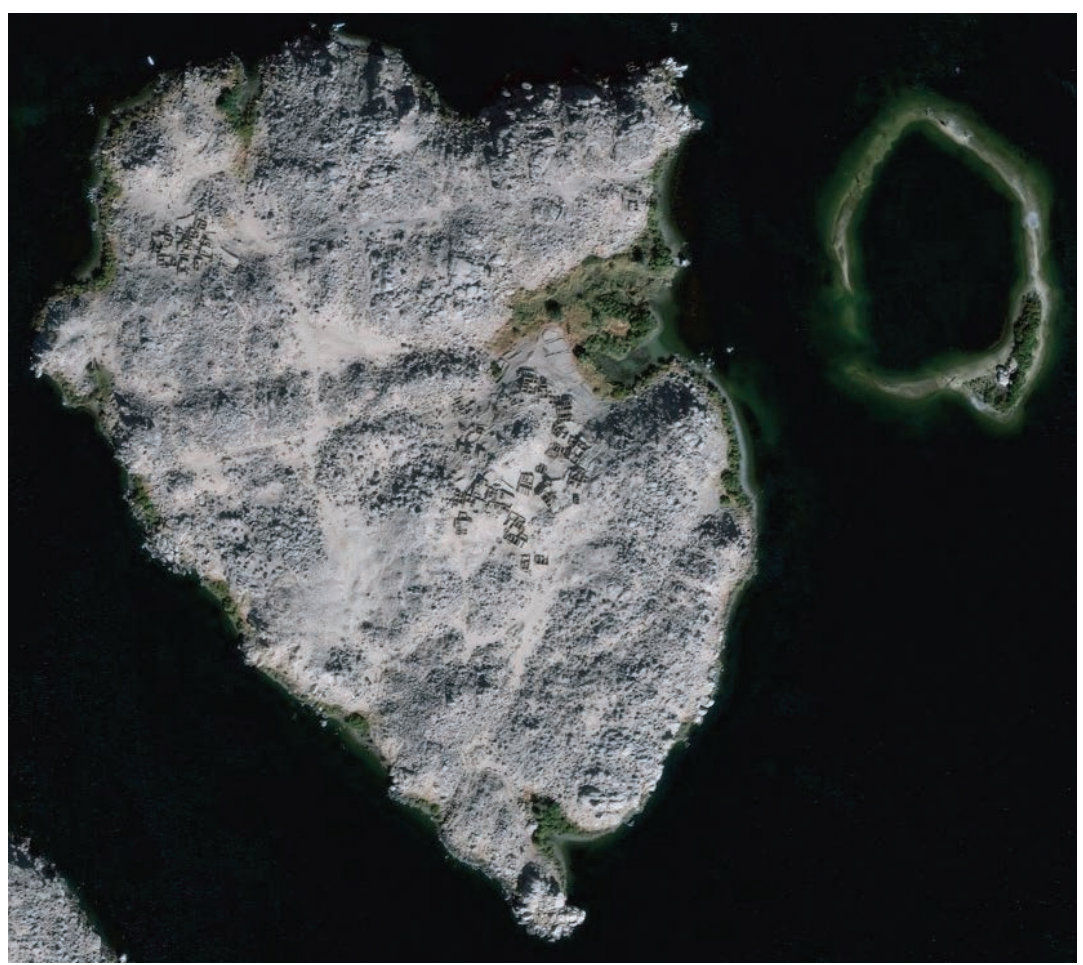

Fig. 13. Vue actuelle de Biggeh (à gauche) et de l'île engloutie de Philae (à droite), sur base de la carte satellite de Bing maps.

\section{Conclusion}

Nous pouvons dire que l'Abaton de Biggeh était un lieu de culte considérable au $\mathrm{I}^{\mathrm{er}}$ millénaire avant notre ère. Nous avons clarifié l'organisation spatiale du lieu : nous connaissons mieux sa topographie, qu'il s'agisse de la description du lieu réelle ou mythique. En effet, nous savons désormais qu'un

\footnotetext{
${ }^{216}$ Ibidem.

217 JUNKER, p. 45-46.

${ }^{218}$ IDEM, p. 46.

${ }^{219}$ IDEM, p. 47.
} 
temple consacré à Osiris-Onnophris et Isis, non à HathorTefnout, était érigé sur l'île et que la tombe et le bosquet sacrés se trouvaient au sud de la crique orientale. Nous avons également mis en lumière l'exubérance et la variété des espèces d'arbres qui composaient ce magnifique bosquet, dont tous les arbres avaient une consonance osirienne, en particulier le majestueux sycomore qui surplombait le sépulcre. Nous avons redéfini la composition et la fonction du bosquet sacré et l'espèce de l'arbre présent sur la tombe a été déterminée. Afin de retourner aux sources, nous avons réalisé de nouvelles traductions et nous avons discuté certaines leçons. De plus, nous avons montré les concordances et les divergences entre les sources. D’une manière générale, nous avons insisté sur la fiabilité des sources classiques concernant l'Abaton. Elles fournissent des informations complémentaires, parfois invérifiables, bien qu'explicables (don direct à Osiris-Nil, rite de la couronne de justification, etc.). Par ailleurs, nous avons prouvé que Diodore évoquait, comme le Décret, la célébration du Rituel du culte divin journalier à l'Abaton et nous avons expliqué l'omission de la tombe osirienne par Sénèque et Lucain. Nous avons avancé une première étymologie du canal proche de l'Abaton. En outre, nous avons mis en évidence le rôle du signe de l'or dans la divinisation du lieu, élément présent à la fois dans les sources textuelles et iconographiques. Enfin, nous avons montré, à la suite de Junker, que l'Abaton n'était qu'une partie de l'île de Biggeh. Les interdictions ne s'étendaient donc pas à l'ensemble de l'île.

Abstract : This article aims at giving an overall view of the real and mythical topography of the Abaton of Biggeh, which housed a relic, the left leg of the God Osiris, in connection with the rituals. After a geographical and archaeological presentation, I will stress in particular the different species of trees growing on and around the Abaton. A new French translation will be provided, with commentary, of the Abaton Decree, in relation to the depictions on the Gate of Hadrian in the temple of Philae. A discussion of all the classical sources in chronological order will follow, in order to draw comparisons with the Egyptian sources. Lastly, the possible location and spatial organization of the Abaton in comparison with other sacred mounds will be addressed.

Keywords : Abaton, Biggeh, Osiris, Abaton Decree, Gate of Hadrian, tomb, mound, topography, relic, grove, tree, leg of Osiris, Nile’s sources, Lucan, Claudianus.

Résumé : Cet article vise à apporter une vue globale de la topographie réelle ou mythique de l'Abaton de Biggeh, qui abritait une relique, la jambe gauche du dieu Osiris, en lien avec les 
rituels. Après une présentation géographique et archéologique, nous insisterons particulièrement sur les différentes espèces d'arbres qui croissaient sur et autour de l'Abaton. Une nouvelle traduction du Décret divin sur l'Abaton de Biggeh, assortie d'un commentaire, sera fournie et mise en relation avec les représentations de la Porte d'Hadrien dans le temple de Philae. S'ensuivra une discussion de toutes les sources classiques dans l'ordre chronologique, en vue d'établir des comparaisons avec les sources égyptiennes. En dernier lieu, nous traiterons de la possible localisation de l'Abaton et de son organisation spatiale.

Mots-clés : Abaton, Biggeh, Osiris, Décret divin concernant l'Abaton, Porte d'Hadrien, tombe, butte, topographie, relique, bosquet, arbre, jambe d'Osiris, sources du Nil, Lucain, Claudien. 
Tableau comparatif des sources textuelles

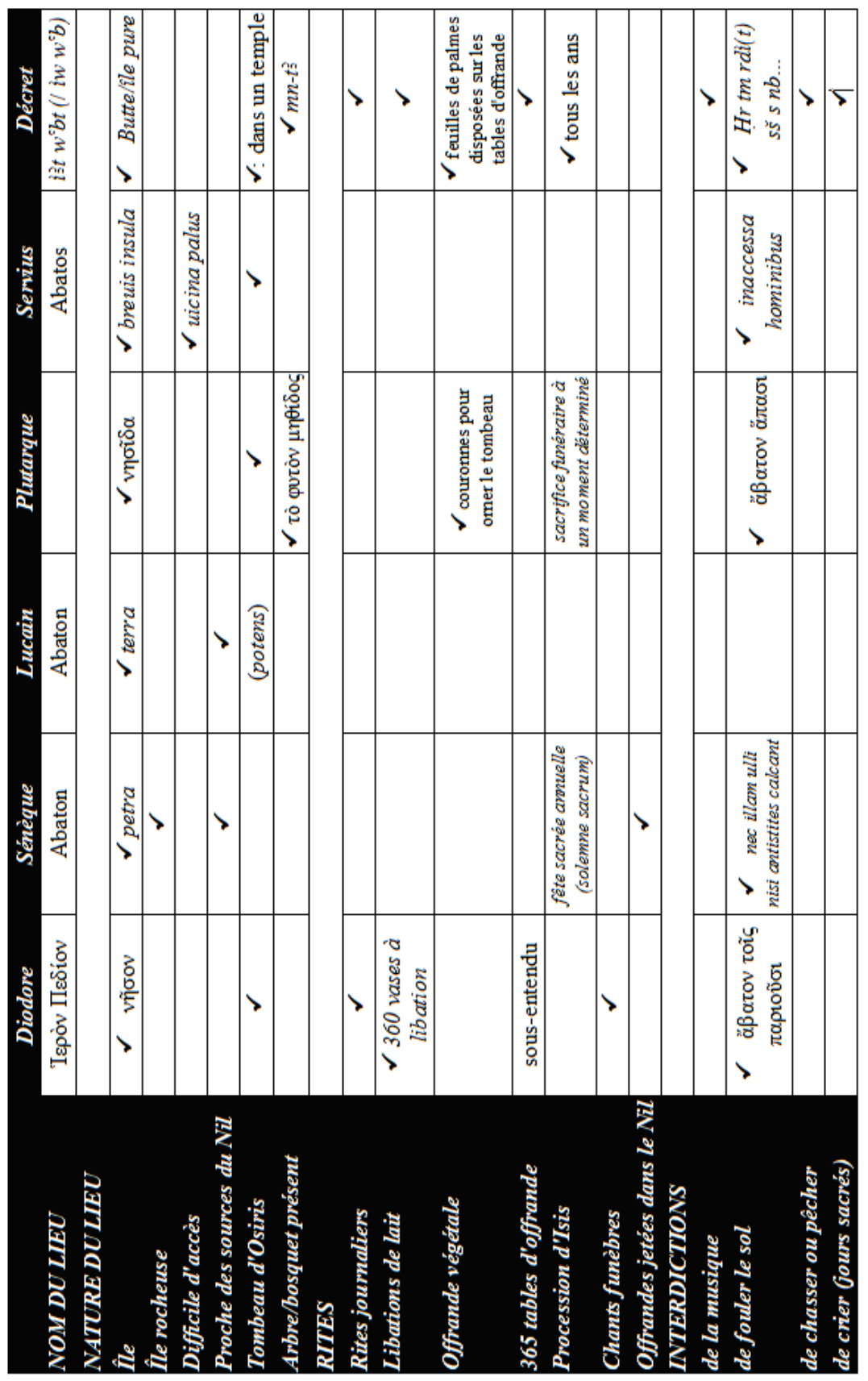

